\title{
Cyanobacterial growth and morphology are influenced by carboxysome positioning and temperature
}

Rees Rillema ${ }^{\mathrm{a} *}$, Joshua S. MacCready ${ }^{\mathrm{a}}$, Anthony G. Vecchiarelli ${ }^{\mathrm{a} \#}$

${ }^{\text {a }}$ Department of Molecular, Cellular, and Developmental Biology, University of Michigan, Ann Arbor, MI, USA.

* Present Address: BioMolecular Science Program, Michigan State University, East Lansing, MI, USA.

Running Title: Carboxysome mispositioning alters cell physiology

${ }^{\#}$ Address correspondence to Anthony G. Vecchiarelli: ave@umich.edu 
1 ABSTRACT: Cyanobacteria are the prokaryotic group of phytoplankton responsible for a

2 significant fraction of global $\mathrm{CO}_{2}$ fixation. Like plants, cyanobacteria use the enzyme Ribulose

3 1,5-bisphosphate Carboxylase/Oxidase $(\mathrm{RuBisCO})$ to fix $\mathrm{CO}_{2}$ into organic carbon molecules via

4 the Calvin-Benson-Bassham cycle. Unlike plants, cyanobacteria evolved a carbon concentrating

5 organelle called the carboxysome - a proteinaceous compartment that encapsulates and

6 concentrates $\mathrm{RuBisCO}$ along with its $\mathrm{CO}_{2}$ substrate. In the rod-shaped cyanobacterium

7 Synechococcus elongatus PCC7942, we recently identified the McdAB system responsible for

8 uniformly distributing carboxysomes along the cell length. It remains unknown what role

9 carboxysome positioning plays with respect to cellular physiology. Here, we show for the first

10 time that a failure to distribute carboxysomes leads to a temperature-dependent decrease in cell

11 growth rate, cell division arrest, cell elongation, asymmetric cell division, and a significant

12 reduction in cellular levels of RuBisCO. Unexpectedly, we also report that even wild-type $S$.

13 elongatus undergoes filamentous growth at the cool, but environmentally-relevant, growth

14 temperature of $20^{\circ} \mathrm{C}$. The findings suggest that carboxysome positioning by the McdAB system

15 functions to maintain the carbon-fixation efficiency of RuBisCO by preventing carboxysome

16 aggregation, which is particularly important at temperatures where rod-shaped cyanobacteria

17 adopt a filamentous morphology.

19 IMPORTANCE: Photosynthetic cyanobacteria are responsible for almost half of global $\mathrm{CO}_{2}$

20 fixation. Due to eutrophication, rising temperatures, and increasing atmospheric $\mathrm{CO}_{2}$

21 concentrations, cyanobacteria have recently gained notoriety for their ability to form massive

22 blooms in both freshwater and marine ecosystems across the globe. Like plants, cyanobacteria

23 use the most abundant enzyme on Earth, RuBisCO, to provide the sole source of organic carbon 
24 required for its photosynthetic growth. Unlike plants, cyanobacteria have evolved a carbon-

25 concentrating organelle called the carboxysome that encapsulates and concentrates RuBisCO

26 with its $\mathrm{CO}_{2}$ substrate to significantly increase carbon-fixation efficiency and cell growth. We

27 recently identified the positioning system that distributes carboxysomes in cyanobacteria.

28 However, the physiological consequence of carboxysome mispositioning in the absence of this

29 distribution system remains unknown. Here we find that carboxysome mispositioning triggers

30 temperature-dependent changes in cell growth and morphology as well as a significant reduction

31 in cellular levels of RuBisCO.

\section{INTRODUCTION}

Cyanobacteria represent a phylum of diverse prokaryotic organisms where many

35 fundamental biological processes have remained largely understudied. As the evolutionary

36 ancestor of algae and plant chloroplasts, all cyanobacteria perform oxygenic photosynthesis and

37 fix carbon dioxide through the Calvin-Benson-Bassham cycle. Unlike chloroplasts,

38 cyanobacteria encapsulate their RuBisCO and carbonic anhydrase within large $(\sim 150 \mathrm{~nm})$

39 selectively permeable protein-based organelles called carboxysomes. This mechanism generates

40 an environment around $\mathrm{RuBisCO}$ that is significantly enriched in $\mathrm{CO}_{2}$, which increases the

41 carboxylation activity of RuBisCO, while simultaneously reducing photorespiration (1).

In the model rod-shaped cyanobacterium Synechococcus elongatus PCC 7942

43 (hereafter S. elongatus), carboxysomes were found to be uniformly distributed down the length

44 of individual cells (2). This equidistant positioning supports equal inheritance of carboxysomes

45 following cell division and maximum diffusion of substrates and products across the

46 carboxysome shell. Carboxysomes are essential for the growth and survival of all cyanobacteria 
47 and are responsible for $\sim 35 \%$ of global carbon-fixation through atmospheric $\mathrm{CO}_{2}$ assimilation

48 (Dworkin, 2006; Kerfeld and Melnicki, 2016). However, it remains unknown how the

49 subcellular organization of carboxysomes influences cyanobacterial physiology; a question of

50 considerable ecological, evolutionary, and biotechnological importance.

Savage et. al. were first to report that a ParA-type ATPase (hereafter McdA

52 - Maintenance of carboxysome distribution $\underline{\text { A}}$ ) is required for positioning carboxysomes in $S$.

53 elongatus (2). ParA family members have well established roles in the segregation of bacterial

54 chromosomes and plasmids $(4,5)$. Less studied are ParA family members shown to be required

55 in the positioning of diverse protein complexes, such as those involved in secretion $(6,7)$,

56 chemotaxis (8-10), conjugation (11), cell division $(12,13)$, and cell motility $(14,15)$, as well as

57 bacterial microcompartments (BMCs), such as the carboxysome $(2,16)$. We recently identified a

58 small novel protein, McdB, responsible for generating dynamic McdA gradients on the nucleoid

59 (16). McdB colocalizes and directly interacts with carboxysomes and removes McdA from the

60 nucleoid in their vicinity. We found that carboxysomes use a Brownian-ratchet mechanism

61 whereby McdB-bound carboxysome motion occurs in a directed and persistent manner toward

62 increased concentrations of McdA on the nucleoid. We also recently found that the McdAB

63 system is widespread among $\beta$-cyanobacteria (17); an incredibly diverse and widely distributed

64 phylum of bacteria that display complex morphologies (18). Together, the data suggest that the

65 equidistant positioning of carbon-fixing carboxysomes in cyanobacteria is important, but the

66 physiological consequences of carboxysome mispositioning in the absence of the McdAB system

67 remain unclear.

When Savage et. al. first identified the McdA requirement for carboxysome positioning,

69 only a minor decrease in $\mathrm{CO}_{2}$ fixation was found in a $\Delta m c d A$ strain, but growth at $30^{\circ} \mathrm{C}$ under 
70 ambient $\mathrm{CO}_{2}$ was the only condition studied (2). Rising sea surface temperatures and coastal

71 eutrophication in marine ecosystems are pervasive effects of climate change (19). Rising

72 temperatures increase enzyme kinetics (20), leading to higher rates of protein synthesis,

73 RuBisCO activity, and photosynthesis (21). Temperature therefore directly influences

74 cyanobacterial growth and metabolic rates $(22,23)$.

75 Here, we show for the first time that a failure to distribute carboxysomes leads to

76 temperature-dependent decreases in growth rate, cell division arrest, cell elongation, asymmetric

77 cell division, and a significant reduction in cellular levels of RuBisCO. We also report that,

78 unexpectedly, wild-type $S$. elongatus undergoes filamentous growth at $20^{\circ} \mathrm{C}$; an environmentally

79 relevant growth temperature for S. elongatus not commonly used in the lab. We propose that

80 carboxysome positioning by the McdAB system functions as part of an autotrophic growth

81 strategy that maintains the carbon-fixation efficiency of RuBisCO by preventing carboxysome

82 aggregation. In the absence of carboxysome positioning or when cells are grown at cooler

83 temperatures, we propose that cell elongation and asymmetric cell division are responses to

84 organic carbon limitation, due to the decreased enzymatic activity of RuBisCO under these

85 conditions.

\section{RESULTS}

88 We performed in vivo microscopy to determine how carboxysome organization was altered

89 in $m c d A, m c d B$, and $m c d A B$ deletion strains compared to wild-type $S$. elongatus. In S. elongatus,

90 each RuBisCO enzyme is composed of eight L Large (RbcL) and eight $\underline{\text { Small }}$ (Rbc $\underline{\mathrm{S}})$ subunits to

91 form $\mathrm{RbcL}_{8} \mathrm{~S}_{8}(24)$. Therefore, to image carboxysomes, the fluorescent protein mTQ (monomeric

92 Turquoise2) was fused to the C-terminus of RbcS to make RbcS-mTQ (see Methods for strain 
93 construction details). $R b c S-m T Q$ was expressed using a second copy of its native promoter

94 (inserted at neutral site 1) in addition to wild-type $r b c S$ at its native locus in wild-type cells as

95 well as in the three deletion strains $-\triangle m c d A, \Delta m c d B$, and $\triangle m c d A B$. The presence of RbcS-mTQ

96 did not alter growth rate (Supplemental Figure S1). Carboxysomes of S. elongatus encapsulate

97 between 800 to 1,500 RuBisCO enzymes (25). Therefore, RbcS-mTQ provided a bright and

98 high-contrast marker for quantifying the subcellular organization of carboxysomes, as previously

99 shown (16). We also performed Phase Contrast imaging to monitor for potential changes in cell

100 morphology, and Chlorophyll fluorescence imaging to verify that cells treated in our analyses

101 were photosynthetically active and therefore viable.

102 In the lab, S. elongatus is typically grown at $32^{\circ} \mathrm{C}$; with a doubling time on the order of

103 several hours depending on growth conditions (temperature, light, and $\mathrm{CO}_{2}$ availability). This

104 was the temperature used in our previous study that identified the McdAB carboxysome

105 positioning system (16). However, S. elongatus was recently shown to grow faster at $40^{\circ} \mathrm{C}(26$,

106 27). Therefore, in anticipation of a growth defect in the absence of carboxysome positioning in

107 our Mcd system mutants, we began our studies by growing cultures at $40^{\circ} \mathrm{C}$ in constant light

108 under ambient $(0.04 \%)$ or high $(2 \%) \mathrm{CO}_{2}$ concentrations.

109

110 Carboxysome mispositioning correlates with minor defects in cellular physiology at $40^{\circ} \mathrm{C}$

111 We first verified that carboxysomes are organized by the McdAB system at $40^{\circ} \mathrm{C}$, as we

112 found previously at $32^{\circ} \mathrm{C}(16)$. We examined carboxysome positioning under high $\mathrm{CO}_{2}$

113 conditions $\left(2 \% \mathrm{CO}_{2}\right)$ to maximize growth. We found that RbcS-mTQ labeled carboxysomes

114 were equally spaced down the long axis of wild-type $S$. elongatus cells (Figure 1A). The $\Delta m c d A$, 
$115 \Delta m c d B$, and $\triangle m c d A B$ mutants lost this uniform positioning of carboxysomes (Figure 1B-D); as

116 observed previously at $32^{\circ} \mathrm{C}(16)$

117 We compared the nearest-neighbor spacing of carboxysome foci as a function of cell

118 length (Figure $1 \mathrm{E})$. Wild-type cells showed uniform carboxysome spacing $(0.55 \pm 0.20 \mu \mathrm{m})$

119 regardless of cell length. All three mutants, on the other hand, displayed a gradual increase in the

120 nearest-neighbor spacing of carboxysome foci as cell length increased. Both the median and

121 variability in spacing were greater in the mutants compared to wild-type (Figure 1F). The

122 increased spacing resulted in fewer carboxysome foci per cell (Figure $\mathbf{1 G}$ ), and within single

123 cells, there were fewer carboxysome foci per unit cell length (Figure 1H). When quantifying the

124 fluorescence intensity (Figure 1I) and size of carboxysome foci (Figure 1J), it became apparent

125 that the increased spacing in all three mutant populations was not likely a result of fewer

126 carboxysomes being assembled, but rather, carboxysomes were coalescing into massive

127 aggregates. Indeed, when comparing carboxysome foci number across cell populations, we find

128 that $\sim 95 \%$ of wild-type cells $(\mathrm{n}=440)$ had three or more foci, whereas $\sim 80 \%$ of all mutant

129 populations had three or fewer foci (Figure $1 \mathbf{K}$ ). Roughly $20 \%$ of cells from all three mutant

130 populations had a single carboxysome aggregate, whereas wild-type cells never had less than two

131 foci. The $40^{\circ} \mathrm{C}$ data shows that the McdAB system not only equally spaces carboxysomes down

132 the cell length, it also serves as an anti-aggregator; preventing carboxysomes from coalescing.

133 We then asked if carboxysome mispositioning affected cell physiology at $40^{\circ} \mathrm{C}$. Wild-

134 type $S$. elongatus cells were $3.1 \pm 0.5$ microns in length (Figure $2 \mathrm{~A}$ ) and $1.25 \pm 0.05$ microns in

135 width (Figure $2 \mathrm{~B}$ ). We found that $\Delta m c d A$ cells were of a similar length and width compared to

136 that of wild-type (Figure 2AB). The $\triangle m c d B$ and $\triangle m c d A B$ cells had a slightly longer median cell

137 length, but a significantly wider distribution (Figure 2A). These mutants were also thinner 
138 compared to wild type (Figure 2B). The presence of both longer and shorter cells suggested

139 asymmetric cell division events. We quantified the frequency of symmetric (mid-cell) versus

140 asymmetric (non-mid-cell) division events and found that asymmetric division was exclusive to

141 the $\triangle m c d B$ and $\triangle m c d A B$ populations (Figure 2C). The data show that while both McdA and

142 McdB are required for positioning carboxysomes, the loss of McdB elicits an asymmetric

143 division phenotype at $40^{\circ} \mathrm{C}$.

144 The changes in cell morphology suggested that, even with high $\mathrm{CO}_{2}$ levels, carboxysome

145 mispositioning may alter cell growth. However, we found only modest reductions in growth rate

146 for all three mutants (Figure 2D-E). Even when grown slowly in ambient $\mathrm{CO}_{2}(0.04 \%)$, we did

147 not observe significant differences in growth rate compared to wild-type (Figure 2F-G). Overall,

148 at $40^{\circ} \mathrm{C}$, carboxysomes are mispositioned in all three Mcd mutants, with moderate increases in

149 carboxysome spacing due to aggregation, which ultimately results in fewer carboxysome foci per

150 cell. We found an asymmetric cell division phenotype exclusive to cell without McdB. But in all

151 deletion strains, growth rate was not significantly slower than wild type, with or without $\mathrm{CO}_{2}$, at

152 this temperature.

154 Carboxysome mispositioning correlates with cell division arrest, cell elongation, and

155 asymmetric cell division at $30^{\circ} \mathrm{C}$

156 We continued our study at $30^{\circ} \mathrm{C}$, a growth temperature closer to what we used to first

157 identify the McdAB carboxysome positioning system (16). As we showed previously, and

158 similar to our $40^{\circ} \mathrm{C}$ data, wild-type $S$. elongatus cells have equally spaced carboxysomes (Figure

159 3A), while in all three mutants, carboxysomes were mispositioned (Figure 3B-D). Wild-type

160 cells displayed the same carboxysome spacing distance $(0.50 \pm 0.20 \mathrm{~mm})$ regardless of cell 
161 length, while all three mutants had increased carboxysome spacing, and variability in spacing, as

162 cell length increased (Figure 3E-F). Intriguingly, we found that mutant cell lengths were

163 significantly longer compared to wild-type. This cell elongation phenotype was more extreme in

164 the $\triangle m c d B$ and $\triangle m c d A B$ mutants, resulting in more distantly spaced carboxysome foci (Figure

$1653 \mathrm{~F})$. The data once again shows that McdB plays a currently unknown role in carboxysome

166 function, separate from its role in positioning with McdA.

168 unit cell length (Figure 3H). Carboxysome foci in all three mutants were significantly larger

169 than that of wild-type, suggesting aggregation (Figure 3I-J). While $\sim 90 \%$ of wild-type cells (n

$170=486)$ had three or more foci, $\sim 70 \%$ of all mutant populations had three or fewer foci (Figure

$1713 \mathrm{~K})$. Again, $\sim 20 \%$ of cells in all three mutant populations contained a single carboxysome

172 aggregate. This is a striking reduction in carboxysome foci when considering the cell elongation

173 phenotype exclusive to the mutant cell lines.

174 As the carboxysome spacing data suggested, all three mutants had significantly longer

175 cell lengths compared to wild-type when grown at $30^{\circ} \mathrm{C}$ (Figure 4A). Median cell width was

176 similar across all strains, however $\Delta m c d B$ and $\Delta m c d A B$ cell populations displayed significantly

177 wider distributions in width (Figure 4B). Once again, the $\triangle m c d B$ and $\triangle m c d A B$ mutant

178 populations displayed a significant number of asymmetrical division events $(\sim 70 \%$ of dividing

179 cells) compared to wild-type or $\Delta m c d A$ (Figure 4C). We propose that carboxysome

180 mispositioning and aggregation at $30^{\circ} \mathrm{C}$ elicits cell division arrest, cell elongation and, when

181 McdB is absent, asymmetric cell division; phenotypes that were largely masked when cells were 182 grown at $40^{\circ} \mathrm{C}$. 
The changes in cell morphology suggested that the mutants may display slower growth

184 rates, even when grown at high $\mathrm{CO}_{2}$. However, that was not the case. Under high $\mathrm{CO}_{2}$ conditions, no significant reduction in growth rate was observed for all three mutants when

186 compared to wild-type (Figure 4D-E). Even when grown in ambient $\mathrm{CO}_{2}$, reductions in growth 187 rate of the mutants were minor (Figure 4F-G). and $\triangle m c d A B$ mutants; with drastic increases in carboxysome spacing due to aggregation, resulting in fewer carboxysome foci per cell. We unveiled a cell elongation phenotype for all

191 three mutant populations, and strikingly, we also found an asymmetric cell division phenotype

192 that was exclusive to cells lacking McdB; a phenotype also found at $40^{\circ} \mathrm{C}$ but exacerbated at

$19330^{\circ} \mathrm{C}$ (compare Panel $\mathrm{C}$ in Figures 2 and 4). Despite these carboxysome aggregation and cell-

194 morphology phenotypes, only minor decreases in growth rate were observed. We propose that

195 carboxysome aggregation decreases the carbon-fixing activity of encapsulated RuBisCO, which 196 triggers an organic carbon-limitation response - cell division arrest, elongation, and asymmetric 197 cell division.

\section{S. elongatus elongates at $20^{\circ} \mathrm{C}$ and this mode of growth is slower in Med system mutants}

A ten degree drop in growth temperature unveiled the physiological consequences of 201 carboxysome mispositioning at $30^{\circ} \mathrm{C}$, which were largely masked at $40^{\circ} \mathrm{C}$. The catalytic rate of

202 carboxysome-encapsulated RuBisCO is often considered the bottle neck of photosynthesis

203 because the enzyme is inefficient (28) and temperature dependent (20). The light reactions of

204 photosynthesis, however, are considered temperature independent $(20,29)$. We therefore decided

205 to study the effects of carboxysome mispositioning when cells were grown at $20^{\circ} \mathrm{C}$, which is 
within the environmentally relevant temperature range - S. elongatus PCC 7942 was originally isolated from a fresh water source in the San Francisco bay area, with an annual temperature range of $8^{\circ} \mathrm{C}$ to $25^{\circ} \mathrm{C}(30)$.

211 temperature (31), but to our knowledge, this is the first time cell morphology has been directly

212 observed. Despite the dramatically long cell lengths, carboxysomes were still robustly aligned

213 down the entire longitudinal axis of the cell (Figure 5A). All three mutants were also elongated,

214 but to a lesser extent, and carboxysomes were clearly mispositioned (Figure 5B-D).

216 even in cells as along as 20 microns (Figure 5E). All three mutants, on the other hand, displayed

217 dramatically increased carboxysome spacing, and variability in spacing, as cell length increased

218 (Figure 5F). Since all cell types dramatically elongated at $20^{\circ} \mathrm{C}$, the loss of carboxysome

219 positioning resulted in a massive reduction in the number of carboxysome foci per cell (Figure

220 5G), and per unit cell length (Figure 5H). Carboxysome foci in all three mutants were

221 significantly larger than that of wild-type, suggesting carboxysome aggregation (Figure 5I-J).

222 While $\sim 90 \%$ of wild-type cells $(\mathrm{n}=388)$ had six or more foci, $\sim 80 \%$ of all mutant populations

223 had less than five (Figure 5K). The data implicates carboxysome positioning by the McdAB

224 system as a requirement for maximizing carbon-fixation in cells that are elongated when grown

225 at cooler but environmentally relevant temperatures.

227 significantly longer than all three mutant populations (Figure 6A). The $\Delta m c d A$ cells were 228 similar in width to that of wild-type, while $\Delta m c d B$ and $\triangle m c d A B$ cell populations were notably 
thinner (Figure 6B). Consistent with the wide distributions in cell length (Figure 6A), a

230 significant fraction of division events at this growth temperature were asymmetric across all cell

231 populations. But the frequency of asymmetric division events was still highest in the strains

232 lacking McdB (Figure 6C).

When growth rates were assayed at high $\mathrm{CO}_{2}$ (Figure 6D-E) or ambient $\mathrm{CO}_{2}$ (Figure 6F-

234 G), we finally found statistically significant reductions in growth rate for all three mutants when

235 compared to wild-type. However, the reductions in growth rate depended on whether McdA or

236 McdB was absent, and whether the cells were grown with high or ambient $\mathrm{CO}_{2}$. First, the $\Delta m c d A$

237 growth rate was 2-times slower than wild-type at high $\mathrm{CO}_{2}$ (Figure 6E). But when grown in

238 ambient $\mathrm{CO}_{2}$, the $\Delta m c d A$ growth rate was similar to wild-type (Figure 6G). It is known that

239 carboxysome quantity significantly increases when $S$. elongatus is grown in ambient $\mathrm{CO}_{2}(32)$.

240 Therefore, our data suggest that with ambient $\mathrm{CO}_{2}$, the greater number of carboxysomes

241 compensates for a loss in their positioning. Alternatively, a decrease in growth rate for $\Delta m c d B$

242 and $\triangle m c d A B$ was found with high- or ambient-levels of $\mathrm{CO}_{2}$ (Figure $6 \mathrm{E}$ and $\mathrm{G}$ ). The data once

243 again shows that McdB plays a key role in carboxysome function outside of its role in

244 positioning with McdA.

Overall, we identified a cell elongation phenotype in wild-type $S$. elongatus cells that

246 occurs when grown at colder, but environmentally relevant temperatures. All three Mcd system

247 mutants elongated to a lesser extent and have aggregated carboxysomes, which resulted in

248 drastically fewer carboxysome foci per cell compared to wild-type. Significant decreases in

249 growth rate were observed, even with high $\mathrm{CO}_{2}$ present. The findings suggest that in Mcd mutant

250 or wild-type cells, colder growth temperatures decrease the enzyme kinetics of RuBisCO to the

251 point where cell division arrest, elongation, and asymmetric cell division is triggered in response 
252 to carbon-limitation. At $30^{\circ} \mathrm{C}$, this response was only found in the Mcd mutants likely due to

253 reduced carbon-fixation efficiency resulting from carboxysome aggregation. At $40^{\circ} \mathrm{C}$, the

254 enzyme kinetics of RuBisCO are fast enough to compensate for carboxysome aggregation, which

255 would explain why Mcd mutants largely displayed cell morphologies and growth rates similar to

256 that of wild-type at higher growth temperatures.

McdAB mutants have significantly decreased levels of intracellular RuBisCO

$\mathrm{RuBisCO}$ is the sole enzyme providing organic carbon to cellular biomass production and

260 the phototrophic growth of S. elongatus. Therefore, we set out to determine if carboxysome

261 mispositioning and the changes in cell morphology of $\mathrm{Mcd} \mathrm{AB}$ mutants at $30^{\circ} \mathrm{C}$ correlated with

262 altered cellular levels of RuBisCO. Immunoblot analysis against the Large subunit of RuBisCO

263 (RbcL) showed that RuBisCO content is roughly half in all three mutants compared to wild-type

264 cells (Figure 7A-B). RbcL content from cell cultures was normalized based on Atp $\beta$ quantity

265 from immunoblot analysis as shown previously $(33,34)$. The data suggest that although the

266 mutants house massive carboxysome aggregates that are much brighter than those uniformly

267 positioned in wild-type cells (Supplemental Figure S2), the loss of a functioning McdAB

268 system results in a reduction in the total cellular content of $\mathrm{RuBisCO}$.

269 We continued our quantification of cellular RuBisCO content using the RbcS-mTQ

270 fluorescence signal. When quantifying the average RbcS-mTQ intensity per cell, only wild-type

271 seemed to increase RuBisCO content in response to decreasing growth temperature (Figure 7C).

272 This finding is consistent with previous studies showing that RuBisCO abundance in

273 phytoplankton populations (35), including cyanobacterial species (44), inversely correlates with

274 growth temperature. We then normalized the RbcS-mTQ signal to cell length to account for the 
275 differences in cell morphology with Mcd system mutants and varying growth temperatures. At

$27640^{\circ} \mathrm{C}, \mathrm{RuBisCO}$ content was similar across all cell populations, albeit more variable in the

277 mutants (Figure 7D). At $30^{\circ} \mathrm{C}$, all three mutants had roughly 2-fold less RuBisCO compared to

278 that of wild type (Figure 7E); a decrease that is consistent with our immunoblot quantification at

$27932^{\circ} \mathrm{C}$ (see Figure 7B). The data confirm that the immunoblot analysis using Atp $\beta$ standardization

280 provided a valid measure of cellular RuBisCO abundance, and that the RbcS-mTQ intensity

281 measurements in vivo are a reasonable proxy for $\mathrm{RuBisCO}$ content. Finally, at $20^{\circ} \mathrm{C}$, all cell

282 populations including wild-type had the lowest levels of $\mathrm{RuBis} C \mathrm{O}$ content when normalized to

283 cell length (Figure 7F) compared to that at higher temperatures (Figure 7D-E). Also, cells

284 without McdB had almost 2-fold less RuBisCO compare to wild-type or $\Delta m c d A$ cells (Figure

285 7F). Overall, our findings suggest that carboxysome mispositioning results in decreased levels of

286 cellular RuBisCO, and unveiled a critical but currently unknown role for McdB in carboxysome

287 integrity and carbon-fixing function.

289 DISCUSSION

290 We recently identified the McdAB system responsible for the equidistant positioning of

291 carboxysomes in the rod-shaped cyanobacterium S. elongatus PCC 7942 (16). We also recently

292 found that McdAB systems are widespread among $\beta$-cyanobacteria (17). These findings suggest

293 important and widespread, but currently unknown, physiological roles for carboxysome

294 positioning. Here, we show for the first time that a failure to distribute carboxysomes leads to a

295 number of temperature-dependent changes in cell physiology: decrease in cell growth rate, cell

296 division arrest, cell elongation, asymmetric cell division, and a significant reduction in cellular

297 levels of RuBisCO. 
At the three temperatures tested $\left(20,30\right.$, and $\left.40^{\circ} \mathrm{C}\right)$, all three mutant cell-types housed

299 few and irregularly spaced carboxysome aggregates, compared to wild-type cells with uniformly-

300 spaced and -sized carboxysome foci. The data here provides quantitative support for our previous

301 findings that the McdAB system equally distributes carboxysomes to opposite sides of the cell to

302 ensure their inheritance following cell division $(2,16)$, akin to ParA-based plasmid partition

303 systems in bacteria (4). But in addition, and particularly important for protein-based cargoes, the

304 McdAB system serves to prevent carboxysome aggregation. This 'anti-aggregation' activity

305 serves as a homeostasis mechanism that regulates carboxysome size, number, composition,

306 positioning, and ultimately, its carbon-fixing function in the cell. It has recently been found that

307 the pyrenoid, the functional analog of the carboxysome in the chloroplasts of the model alga

308 Chlamydomonas, is also spatially regulated and this activity affects carbon-fixation (36). It

309 remains to be seen if other BMCs also use spatial regulation mechanisms to avoid aggregation

310 during their self-assembly to optimize enzymatic efficiency.

\section{Physiological defects associated with carboxysome mispositioning are temperature-}

\section{3 dependent.}

314 Despite the drastic mispositioning and aggregation of carboxysomes in the $m c d A, m c d B$,

315 and $m c d A B$ deletion strains of $S$. elongatus, only minor changes in cell morphology and growth

316 rate were found when compared to wild-type at the most optimal growth temperature used in this

317 study $\left(40^{\circ} \mathrm{C}\right)$ (Figures 2$)$. At $30^{\circ} \mathrm{C}$ however, all three mutants displayed filamentous growth, and

318 a significant fraction of cell division events in the mutant populations lacking McdB were

319 asymmetric (Figure 4). Despite these changes to cell morphology, the growth rates were similar

320 to that of wild-type; even in ambient $\mathrm{CO}_{2}$. At our coldest but environmentally relevant growth 
321 temperature of $20^{\circ} \mathrm{C}$, we found that all cell populations, even wild-type, underwent filamentous

322 growth and asymmetric cell division (Figure 6). Wild-type cells at $20^{\circ} \mathrm{C}$ were as much as 5 to

32310 -times longer than the median length when grown at $30^{\circ} \mathrm{C}$ or $40^{\circ} \mathrm{C}$. Even in these extremely

324 elongated cells, the McdAB system robustly distributed carboxysomes down the entire cell

325 length (Figure 5A). This mode of filamentous growth was slower in all Mcd system mutants,

326 resulting in significantly shorter filaments compared to wild-type (Figure 6). Overall, we find

327 temperature-dependent physiological defects associated with carboxysome mispositioning and

328 aggregation; phenotypes that were masked at high growth rates and temperatures typically used

329 in the lab, and unveiled at lower but environmentally relevant temperatures.

331 Cell division arrest, filamentation, and asymmetric cell division - A stress response to

332 carbon-limitation?

333 Many bacteria can change shape in response to growth conditions (37). E. coli and B.

334 subtilis produce larger cells under nutrient-rich conditions and smaller cells under nutrient-

335 limited conditions $(38,39)$. Pseudomonas aeruginosa elongates to enhance nutrient uptake

336 during carbon and nitrogen starvation (40); Caulobacter crescentus cells increase cell area in

337 response to phosphate starvation (41); and abundant human gut species such as Bacteriodes

338 thetaiotaomicron elongate under sugar-limited conditions (42). Our findings suggest that $S$.

339 elongatus filamentation and asymmetric cell division are responses triggered by organic carbon-

340 limitation, resulting from reduced carbon-fixation activity of RuBisCO in this obligate

341 photoautotroph. Cell filamentation (i) prevents the birth of cells devoid of carboxysomes, (ii)

342 gives the cell an opportunity to increase carbon-fixation by producing more RuBisCO as a larger

343 aggregate, or by nucleating the formation of additional carboxysomes de novo elsewhere along 
344 the elongated cell and (iii) the increased cell-surface area would increase the light-harvesting

345 capability for photochemistry.

A carbon-limitation response parsimoniously explains the two triggers identified here: (1)

347 carboxysome aggregation and (2) colder growth temperatures. What is the mechanism behind the

348 carboxysome aggregation trigger? All Mcd system mutants displayed significant reductions in

349 their total cellular RuBisCO content (Figure 7). Therefore, carboxysome aggregation could

350 trigger the carbon-limitation response simply due to lower levels of RuBisCO as a result of

351 losses in carboxysome integrity and leakage, enzyme stability, and/or degradation. Alternatively,

352 wild-type cells have carboxysomes of a homogenous size, and as cells grow, so do the number of

353 carboxysomes and their net surface area. The net surface area of the carboxysome shell, where

354 RuBisCO substrates and products interface with the cytoplasm, significantly decreases due to

355 carboxysome aggregation. As a result, substrate and product permeability would suffer, which

356 could lead to decreased carbon-fixation rates by encapsulated RuBisCO. It is therefore also

357 possible that the carbon-limitation response is triggered by decreased RuBisCO activity due to

358 decreases in the effective surface area of aggregated carboxysomes. These two proposals are not

359 necessarily mutually exclusive from one another. Consistent with these proposals, it was recently

360 found in Synechococcus sp. PCC 7002 that mispositioning of inactivated carboxysomes towards

361 the cell poles is strongly correlated with their rapid degradation (35).

362 We propose this adaptive response to carbon-limitation is also triggered by low

363 temperature growth, even in wild-type $S$. elongatus. At high temperature (i.e. $\left.40^{\circ} \mathrm{C}\right), \mathrm{RuBisCO}$

364 activity is high (43) and sufficient to compensate for carboxysome mispositioning and RuBisCO

365 aggregation in Mcd system mutants. Therefore, the carbon-limitation response is not triggered.

366 At $30^{\circ} \mathrm{C}, \mathrm{RuBisCO}$ activity is still high enough to prevent a carbon-limitation response in wild- 
367 type cells, but not in Mcd mutants with few and aggregated carboxysomes. As a result, cell

368 filamentation is triggered only in the Mcd mutants. At $20^{\circ} \mathrm{C}, \mathrm{RuBisCO}$ activity has reduced to a

369 level that, even in wild-type cells, triggers the carbon-limitation response. Mcd mutants are

370 starved for carbon to the point where growth is slowed, resulting in shorter filaments compared

371 to wild-type.

Spatial regulation of carboxysomes influences $\mathrm{RuBisCO}$ activity and abundance

Psychrophilic phytoplankton species deal with low temperatures, well below the thermal

375 optimum of most enzymes, by increasing the abundance of RuBisCO (35). It has recently been

376 found that low temperature growth $\left(18\right.$ to $\left.22^{\circ} \mathrm{C}\right)$ results in increased $\mathrm{RuBisCO}$ levels in the

377 marine cyanobacterium Synechococcus PCC 7002, compared to growth at $26^{\circ} \mathrm{C}$ or $30^{\circ} \mathrm{C}(44)$.

378 This trend was also observed in natural phytoplankton assemblages across a wide latitudinal

379 range (35). Consistently, we found here that the RbcS-mTQ signal within carboxysome foci, and

380 within the entire cell, inversely correlated with decreasing growth temperatures.

$381 \quad$ Previous studies have also shown positive relationships between growth rate and

382 RuBisCO abundance $(35,44-48)$. Elevated carbon fixation rates during blooms in polar regions

383 have been shown to be associated with several-fold increases in RuBisCO. Twenty degrees

384 Celsius is well below the thermal optimum for RuBisCO activity (49), and well below the

385 optimal growth temperature of S. elongatus. We therefore conclude that increasing RuBisCO

386 abundance and triggering cell elongation both represent acclimation responses that compensate

387 for the decreased catalytic rate of $\mathrm{RuBisCO}$ at low-temperature growth. This response is further

388 compounded when carboxysomes are mispositioned and aggregated in our Mcd mutants. It is

389 important to note that filamentation occurred here under high $\mathrm{CO}_{2}-$ a condition whereby $S$. 
elongatus does not require the carbon-concentrating activity of carboxysomes for growth (50).

391 Therefore, the evidence further supports that it is not $\mathrm{CO}_{2}$ substrate limitation causing

392 filamentation, but rather RuBisCO activity that is significantly compromised when complexed in

393 carboxysome aggregates or when cells are grown at colder temperatures. These findings shed

394 light on the importance of the McdAB system in maximizing the carbon-fixation activity of

395 RuBisCO by preventing aggregation during carboxysome self-assembly.

Overall, we show that carboxysomes are organized by the McdAB system in cyanobacteria and can appropriately respond to variability in RuBisCO abundance and activity

398 along a wide temperature gradient. Our results suggest that carboxysome homeostasis provided

399 by the McdAB system is part of an autotrophic growth strategy in elongated cells - RuBisCO

400 abundance increases and is distributed into homogeneously-sized carboxysomes at low

401 temperature to overcome the lower catalytic rates of this temperature-dependent enzyme (35).

McdB plays a role in carboxysome function outside of its positioning with McdA

406 McdB plays a currently unknown but critical role in carboxysome function, outside of its role in

407 positioning with McdA. Consistently, our recent bioinformatics analysis of McdAB systems

408 across cyanobacteria identified numerous species with orphan McdBs, once again suggesting

409 functional roles independent of McdA (17). We have also shown previously via bacterial two-

410 hybrid analysis that McdA does not physically associate with any carboxysome component,

411 while McdB directly interacts with a number of shell proteins (16). We have also recently found

412 that purified McdB undergoes Liquid-Liquid Phase-Separation (LLPS) in vitro (17). This activity 
413 is intriguing given recent studies showing that both $\alpha$ - and $\beta$-carboxysomes, as well as the algal

414 pyrenoid, have intrinsically-disordered proteins that from liquid-like condensates with RuBisCO

415 (51-53). Collectively, these studies suggest that LLPS is a common feature underlying

416 carboxysome biogenesis. It is intriguing to speculate that the LLPS activity of McdB and other

417 carboxysome components are related and potentially influence each other.

419 Cold growth temperature triggers elongation and asymmetric cell division

420 Across the bacterial world, complex systems maintain cell-size homeostasis. We find

421 here that $S$. elongatus maintains cell-size homeostasis when grown at $30^{\circ} \mathrm{C}$ or $40^{\circ} \mathrm{C}$, but

422 undergoes filamentation when grown at the environmentally-relevant temperature of $20^{\circ} \mathrm{C}$. A

423 growing number of bacterial species are known to elongate into a filamentous morphology

424 amidst environmental changes to promote survival. For example, E. coli cells become

425 filamentous during infection $(54,55)$, and during DNA damage, the SOS response blocks cell

426 division until damage has been repaired, resulting in elongation (56). Several other forms of

427 stress have been shown to induce elongation, including host environment, antibiotics, nutrient

428 access, $\mathrm{pH}$, heat shock, and osmotic fluctuations (57-60). Bacteria can clearly exist in diverse

429 morphological states, in part dictated by their environment $(37,61)$.

$430 \quad$ To our knowledge, we find here the first example of bacterial filamentation caused by

431 cold-growth temperature. We propose colder temperatures trigger filamentation indirectly as a

432 carbon-limitation response due to the reduced carbon-fixing activity of RuBisCO. Alternatively,

433 transition into a filamentous morphology has been proposed to confer advantages, such as

434 avoiding phagocytosis via the host immune response $(54,55,57,61)$ or to protect against

435 predation in aquatic environments $(58,62-64)$. It is attractive to speculate that the growth 
436 temperature of $20^{\circ} \mathrm{C}$ coincides with the seasonal temperature during which predation occurs (63).

437 That is, S. elongatus may use temperature as a cue to elongate so as to avoid planktivorous

438 protists. Consistent with this possibility, previous studies have demonstrated that several

439 freshwater bacteria, including Caulobacter crescentus (58), exhibit high phenotypic plasticity

440 and can transition to a filamentous morphology - a transition that may be specifically triggered

441 in the presence of a size-selective protistan predator $(63,65,66)$. It is possible that some aquatic

442 bacteria have evolved to undergo filamentation at temperatures that coincide with grazing

443 season.

444 Several studies have characterized the mechanisms by which bacterial filamentation is

445 induced, particularly under DNA damage or exposure to antibiotics (56). But how bacterial cells

446 enter and exit these filamentous states to ensure survival during changes in environment remains

447 poorly characterized and is a recent question of interest. We find here that S. elongatus forms

448 filaments when grown at low temperature or when carboxysomes are mispositioned. When these

449 filaments divide, it is asymmetric - forming a daughter cell of 'normal' length. It has been

450 recently shown that $S$. elongatus can also be induced to filament under dim-light stress, and then

451 divides asymmetrically to form daughter cells of the correct size when brought back into well-lit

452 conditions (67). Somewhat related, chlorophyll fluorescence along the cell length of our Mcd

453 mutants was much more heterogeneous, particularly at $20^{\circ} \mathrm{C}$, compared to wild-type (see Figure

454 5A-D). It should be noted that in addition to sensing light and inorganic carbon substrates, $S$.

455 elongatus responds to lowering temperatures by slowing and even turning off circadian rhythms;

456 thereby down regulating cell growth, division, and metabolic flux $(68,69)$.

457 The Min system has been shown to play a role in the asymmetric cell division and

458 daughter-cell sizing of filamentous E. coli (60), V. parahaemolyticus $(70,71)$, and S. elongatus 
459 (67). Recent findings suggest that division restoration at the poles of these filaments is regulated

460 by a combination of Min oscillations, FtsZ levels and terminus segregation, resulting in daughter

461 cells of the right length $(72,73)$. The mechanism by which filamentation and asymmetric

462 division occurs in S. elongatus is an area of future research. Taken together, the conserved ability

463 for various bacterial species to undergo filamentation and morphological recovery, some of

464 which showing direct selective benefits, strongly suggests that this differentiation plays an

465 important role in survival and proliferation.

MATERIALS AND METHODS

469 Construct designs. All constructs in this study were generated using Gibson Assembly (74)

470 from synthetized dsDNA and verified by sequencing. Constructs contained flanking DNA that

471 ranged from 500 to $1500 \mathrm{bp}$ in length upstream and downstream of the targeted insertion site to

472 promote homologous recombination into target genomic loci (75).

474 Generation of Bacterial Strains. All Synechococcus elongatus PCC7942 transformations were 475 performed as previously described (75). Plasmid constructs of $m c d A, m c d B$, and $m c d A B$

476 deletions were created by replacing the respective coding sequences with a kanamycin resistance

477 cassette. All fluorescent strains were transformed using plasmid pAH40, which contains a

478 chloramphenicol resistance cassette and a second copy of the $r b c S$ promoter and gene, attached

479 at the 3' end with the gene encoding for fluorescent protein mTurquoise2 (mTQ) and separated

480 with a GSGSGS linker, inserted into neutral site 1. Transformed cells were plated on BG-11

481 agar. Single colonies were picked into 96-well plates containing $300 \mu \mathrm{L}$ of BG-11 with $6.35 \mathrm{ug}$ 
$482 \mathrm{ml}^{-1}$ kanamycin or $3.125 \mathrm{ug} \mathrm{ml}^{-1}$ chloramphenicol. Concentrations of both respective antibiotics

483 were gradually increased to $12.5 \mu \mathrm{g} \mathrm{ml}^{-1}$. Cultures were verified for complete insertion via PCR

484 and removed from antibiotics for experiments.

486 Growth Conditions. Both wild-type and mutant Synechococcus elongatus PCC7942 strains

487 were grown in $125 \mathrm{~mL}$ culture flasks (Corning) in $50 \mathrm{~mL}$ BG-11 (Sigma) medium buffered with

$4881 \mathrm{~g} \mathrm{~L}^{-1}$ HEPES to $\mathrm{pH} 8.3$ shaken at $130 \mathrm{rpm}$ or on BG-11 plates containing $1.5 \%(\mathrm{w} / \mathrm{v})$ agar. All

489 strains were maintained and grown under constant LED illumination of $100 \mu \mathrm{E} \mathrm{m}^{-2} \mathrm{~s}^{-1}$ at either

$49020^{\circ} \mathrm{C}, 30^{\circ} \mathrm{C}$, or $40^{\circ} \mathrm{C}$ in $2 \%$ or $0.04 \% \mathrm{CO}_{2}$ as specified. Cultures grown in $0.04 \% \mathrm{CO}_{2}$ were

491 grown in air with no additional $\mathrm{CO}_{2}$. Cultures were regularly diluted with fresh medium to

492 maintain exponential growth phase for subsequent imaging and immunoblot analyses. For

493 cloning, One Shot ${ }^{\mathrm{TM}}$ TOP10 Chemically Competent E. coli (ThermoFisher) were grown

494 aerobically at $37^{\circ}$ in Luria-Broth medium.

496 Fluorescence microscopy. Microscopy was performed using exponentially growing cells at an

497 OD of 0.4. Two milliliters of culture were spun down at 15,000 x g for $60 \mathrm{~s}$, resuspended in 100

$498 \mu \mathrm{L}$ of BG-11. Five microliters were transferred to a square $1.5 \%$ agarose + BG-11 pad, which

499 was then flipped onto a $35 \mathrm{~mm}$ cell culture dish with a \#1.5 glass coverslip bottom (ManTek).

500 All images were captured using a Nikon Eclipse Ti2 inverted microscope with a PlanApo

501 Objective lens (100x, 1.45NA, oil immersion), with phase contrast transillumination, and with a

502 SOLA LED light source for imaging chlorophyll fluorescence (Excitation: 560/40nm (540-

503 580nm), Emission: 630/70nm (593-668nm), Dichroic Mirror: 585nm) and RbcS-mTQ

504 fluorescence (Excitation: 436/20nm (426-446nm), Emission: 480/40nm (460-500nm), Dichroic 
Mirror: 455nm). Images were acquired using a Photometrics Prime 95B Back-illuminated

sCMOS Camera. Image analysis was performed using Fiji (76) and the MicrobeJ plugin (77).

508 Growth Curve Measurements. Cultures were inoculated at a starting $\mathrm{OD}_{750}$ of 0.1-0.2 with

509 fresh BG-11. Cell growth was monitored at OD 750 using a DS-11 Spectrophotometer (DENOVI)

510 at the specified time points. Growth rates were calculated using the linear portion of the

511 exponential phase of growth. Error bars represent the standard deviation from three biological

512 replicates that were recorded from different culture flasks.

514 MicrobeJ quantification. Multiple fields of view were taken for each cell strain using three

515 channels: Phase contrast provided cell perimeters, and fluorescence microscopy provided

516 chlorophyll autofluorescence and RbcS-mTQ intensities. These data were analyzed using

517 MicrobeJ (77). In each cell-line, cell length detection was performed using the rod-shaped

518 descriptor and thresholding set to $0.4 \mu \mathrm{m}<$ area $<\max , 0.71 \mu \mathrm{m}<$ width range $<2 \mu \mathrm{m}, 0 \mu \mathrm{m}<$

519 width variation $<0.2 \mu \mathrm{m}$, and $0 \mu \mathrm{m}<$ angularity amplitude $<0.35 \mu \mathrm{m}$. Carboxysome detection

520 was performed using the point function with a tolerance of 20 and an intensity minimum of 500.

521 Associations, shape descriptors, profiles, and distances were recorded for each strain. All

522 MicrobeJ quantification was also verified manually. Graphs and statistical analyses were 523 generated with Graph Pad Prism.

525 Immunoblot Analysis. Cells were lysed with a Qsonica sonication system (20 cycles - 30 s on,

$52610 \mathrm{~s}$ off at $30 \%$ power) in $0.5 \mathrm{~mL}$ RuBisCO extraction buffer (50 mM EPPS at $\mathrm{pH} 8.1,1 \%$ PVPP, $5271 \mathrm{mM}$ EDTA, $10 \mathrm{mM}$ DTT, 0.1\% Triton, and sigma protease inhibitor). Laemmli sample buffer 
$528(0.1 \mathrm{~mL}$ of $4 \mathrm{x})$ was added to lysate prior to loading $10 \mu \mathrm{L}$ on a $4 \%-12 \%$ Bis-Tris NuPAGE gel

529 (Invitrogen). Gels were transferred onto a Mini-size polyvinylidene difluoride membrane (Bio-

530 Rad) using a Trans-Blot Turbo system (Bio-Rad). The membrane was immunoprobed using

531 rabbit polyclonal antisera against $\mathrm{RbcL}$ and the beta subunit of ATP synthase, AtpB (Agrisera)

532 and then goat anti-rabbit IgG secondary antibody (LI-COR). Membrane signals were visualized

533 and quantified at $600 \mathrm{~nm}$ using LI-COR Image Studio. For each sample, there were three

534 replicates from the same cell lysate. We normalized RbcL signal using AtpB; a method

535 previously used in Zhang et al., 2012 and specifically with S. elongatus PCC7942 in Sun et al.,

$5362016(33,34)$.

\section{ACKNOWLEDGMENTS}

539 We would like to thank Drs. Lyle Simmons, Vincent Denef, and Daniel Ducat for providing

540 critical feedback in experimental direction and data interpretation. We would also like to thank

541 Pusparanee Anne Hakim for experimental assistance and critical reading of the manuscript.

\section{REFERENCES:}

544 1. Rae BD, Long BM, Badger MR, Price GD. 2013. Functions, compositions, and evolution

545 of the two types of carboxysomes: Polyhedral microcompartments that facilitate $\mathrm{CO} 2$

546 fixation in cyanobacteria and some proteobacteria. Microbiol Mol Biol Rev.

547 2. Savage DF, Afonso B, Chen AH, Silver PA. 2010. Spatially Ordered Dynamics of the $548 \quad$ Bacterial Carbon Fixation Machinery. Science (80- ) 327:1258-1261.

549 3. Kerfeld CA, Melnicki MR. 2016. Assembly, function and evolution of cyanobacterial $550 \quad$ carboxysomes. Curr Opin Plant Biol 31:66-75. 
551 4. Baxter JC, Funnell BE. 2014. Plasmid Partition Mechanisms. Microbiol Spectr 2.

552 5. Badrinarayanan A, Le TBK, Laub MT. 2015. Bacterial Chromosome Organization and

553 Segregation. Annu Rev Cell Dev Biol 31:171-199.

554 6. Viollier PH, Sternheim N, Shapiro L. 2002. Identification of a localization factor for the 555 polar positioning of bacterial structural and regulatory proteins. Proc Natl Acad Sci USA $556 \quad 99: 13831-13836$.

557 7. Perez-Cheeks BA, Planet PJ, Sarkar IN, Clock SA, Xu Q, Figurski DH. 2012. The product 558 of tadZ, a new member of the parA/minD superfamily, localizes to a pole in

559 Aggregatibacter actinomycetemcomitans. Mol Microbiol 83:694-711.

560 8. Thompson SR, Wadhams GH, Armitage JP. 2006. The positioning of cytoplasmic protein $561 \quad$ clusters in bacteria. Proc Natl Acad Sci USA 103:8209-8214.

562 9. Ringgaard S, Schirner K, Davis BM, Waldor MK. 2011. A family of ParA-like ATPases 563 promotes cell pole maturation by facilitating polar localization of chemotaxis proteins. $564 \quad$ Genes Dev 25:1544-1555.

565 10. Alvarado A, Kjær A, Yang W, Mann P, Briegel A, Waldor MK, Ringgaard S. 2017.

566 Coupling chemosensory array formation and localization. Elife 6.

567 11. Atmakuri K, Cascales E, Burton OT, Banta LM, Christie PJ. 2007. Agrobacterium

$568 \quad$ ParA/MinD-like VirC1 spatially coordinates early conjugative DNA transfer reactions.

$569 \quad$ EMBO J 26:2540-2551.

570 12. Raskin DM, De Boer PAJ. 1999. Rapid pole-to-pole oscillation of a protein required for 571 directing division to the middle of Escherichia coli. Proc Natl Acad Sci U S A.

572 13. Jordan A, Chandler J, MacCready JS, Huang J, Osteryoung KW, Ducat DC. 2017.

573 Engineering Cyanobacterial Cell Morphology for Enhanced Recovery and Processing of 
Biomass. Appl Env Microbiol 83.

575 14. Youderian P, Burke N, White DJ, Hartzell PL. 2003. Identification of genes required for adventurous gliding motility in Myxococcus xanthus with the transposable element mariner. Mol Microbiol 49:555.

15. Kusumoto A, Shinohara A, Terashima H, Kojima S, Yakushi T, Homma M. 2008. Collaboration of FlhF and FlhG to regulate polarflagella number and localization in Vibrio

16. MacCready JS, Hakim P, Young EJ, Hu L, Liu J, Osteryoung KW, Vecchiarelli AG, Ducat DC. 2018. Protein gradients on the nucleoid position the carbon-fixing organelles of cyanobacteria. Elife 7.

17. MacCready JS, Basalla JL, Vecchiarelli AG. 2020. Origin and Evolution of Carboxysome Positioning Systems in Cyanobacteria. Mol Biol Evol 37:1434-1451.

18. Shih PM, Wu D, Latifi A, Axen SD, Fewer DP, Talla E, Calteau A, Cai F, Tandeau De

19. Doney SC, Ruckelshaus M, Emmett Duffy J, Barry JP, Chan F, English CA, Galindo HM,

594 20. Geider RJ. 1987. Light and Temperature Dependence of the Carbon to Chlorophyll a 
597 21. Raven JA, Geider RJ. 1988. Temperature and algal growth. New Phytol.

598 22. Eppley R. 1972. Temperature and phytoplankton growth in the sea. Fish Bull.

599 23. Chen B, Liu H, Huang B, Wang J. 2014. Temperature effects on the growth rate of marine

600 picoplankton. Mar Ecol Prog Ser.

601 24. Tabita FR, Hanson TE, Satagopan S, Witte BH, Kreel NE. 2008. Phylogenetic and evolutionary relationships of RubisCO and the RubisCO-like proteins and the functional lessons provided by diverse molecular formsPhilosophical Transactions of the Royal Society B: Biological Sciences.

605 25. Sun Y, M Wollman AJ, Huang F, Leake MC, Liu L-N. 2019. Single-Organelle Dependent on the Environment. Plant Cell Adv Publ.

26. Ohbayashi R, Nakamachi A, Hatakeyama TS, Watanabe S, Kanesaki Y, Chibazakura T,

611 27. Yu J, Liberton M, Cliften PF, Head RD, Jacobs JM, Smith RD, Koppenaal DW, Brand JJ, Pakrasi HB. 2015. Synechococcus elongatus UTEX 2973, a fast growing cyanobacterial chassis for biosynthesis using light and $\mathrm{CO}_{2}$. Sci Rep.

614 28. Erb TJ, Zarzycki J. 2018. A short history of RubisCO: the rise and fall (?) of Nature's predominant $\mathrm{CO} 2$ fixing enzyme. Curr Opin Biotechnol.

616 29. Ensminger I, Busch F, Huner NPA. 2006. Photostasis and cold acclimation: Sensing low 617 temperature through photosynthesis. Physiol Plant.

618 30. Welkie DG, Rubin BE, Diamond S, Hood RD, Savage DF, Golden SS. 2019. A Hard Day’s Night: Cyanobacteria in Diel Cycles. Trends Microbiol. 
620 31. Burns RA, MacDonald CD, McGinn PJ, Campbell DA. 2005. Inorganic carbon repletion

621 disrupts photosynthetic acclimation to low temperature in the cyanobacterium

$622 \quad$ Synechococcus elongatus. J Phycol.

623 32. Sun Y, Wollman AJM, Huang F, Leake MC, Liu LN. 2019. Single-organelle

624 quantification reveals stoichiometric and structural variability of carboxysomes dependent

625 on the environment. Plant Cell.

626 33. Sun Y, Casella S, Fang Y, Huang F, Faulkner M, Barrett S, Liu LN. 2016. Light

627 modulates the biosynthesis and organization of cyanobacterial carbon fixation machinery

628 through photosynthetic electron flow. Plant Physiol 171:530-541.

629 34. Zhang P, Eisenhut M, Brandt AM, Carmel D, Silén HM, Vass I, Allahverdiyeva Y,

630 Salminen TA, Aro EM. 2012. Operon flv4-flv2 provides cyanobacterial photosystem ii

631 with flexibility of electron transfer. Plant Cell.

632 35. Young JN, Goldman JAL, Kranz SA, Tortell PD, Morel FMM. 2015. Slow carboxylation

633 of Rubisco constrains the rate of carbon fixation during Antarctic phytoplankton blooms.

$634 \quad$ New Phytol.

635 36. Itakura AK, Chan KX, Atkinson N, Pallesen L, Wang L, Reeves G, Patena W, Caspari O,

636 Roth R, Goodenough U, McCormick AJ, Griffiths H, Jonikas MC. 2019. A Rubisco-

637 binding protein is required for normal pyrenoid number and starch sheath morphology in

638 \&lt;em\&gt;Chlamydomonas reinhardtii\&lt;/em\&gt; Proc Natl Acad Sci 116:18445 LP _

$639 \quad 18454$.

640 37. Kysela DT, Randich AM, Caccamo PD, Brun Y V. 2016. Diversity Takes Shape:

641 Understanding the Mechanistic and Adaptive Basis of Bacterial Morphology. PLOS Biol

$642 \quad 14: \mathrm{e} 1002565$. 
643 38. Jun S, Si F, Pugatch R, Scott M. 2018. Fundamental principles in bacterial physiology-

644 history, recent progress, and the future with focus on cell size control: a review. Reports

$645 \quad$ Prog Phys 81:056601.

646 39. Sargent MG. 1975. Control of cell length in Bacillus subtilis. J Bacteriol 123.

647 40. Steinberger RE, Allen AR, Hansma HG, Holden PA. 2002. Elongation correlates with

648 nutrient deprivation in Pseudomonas aeruginosa - Unsaturated biofilms. Microb Ecol

$649 \quad 43: 416-423$.

650 41. Gonin M, Quardokus EM, O’Donnol D, Maddock J, Brun Y V. 2000. Regulation of stalk 651 elongation by phosphate in Caulobacter crescentus. J Bacteriol 182:337-347.

652 42. Rangarajan AA, Koropatkin NM, Biteen JS. 2020. Nutrient-dependent morphological 653 variability of Bacteroides thetaiotaomicron. Microbiology 166:624-628.

654 43. Galmés J, Hermida-Carrera C, Laanisto L, Niinemets Ü. 2016. A compendium of temperature responses of Rubisco kinetic traits: variability among and within photosynthetic groups and impacts on photosynthesis modeling. J Exp Bot 67:5067-5091.

657 44. Fernández-González C, Pérez-Lorenzo M, Pratt N, Moore CM, Bibby TS, Marañón E. 658 2020. Effects of Temperature and Nutrient Supply on Resource Allocation, Photosynthetic 659 Strategy, and Metabolic Rates of Synechococcus sp. J Phycol.

660 45. Falkowski PG, Sukenik A, Herzig R. 1989. Nitrogen limitation in Isochrysis Galbana (Haptophyceae). II. Relative abundance of chloroplast proteins. J Phycol.

662 46. Raven JA, Johnston AM. 1991. Mechanisms of inorganic-carbon acquisition in marine 663 phytoplankton and their implications for the use of other resources. Limnol Oceanogr.

664 47. Losh JL, Morel FMM, Hopkinson BM. 2012. Modest increase in the C:N ratio of N665 limited phytoplankton in the California Current in response to high CO2. Mar Ecol Prog 
Ser.

667 48. Losh JL, Young JN, Morel FMM. 2013. Rubisco is a small fraction of total protein in marine phytoplankton. New Phytol.

669 49. Galmés J, Aranjuelo I, Medrano H, Flexas J. 2013. Variation in Rubisco content and activity under variable climatic factors. Photosynth Res.

671 50. Cameron JC, Wilson SC, Bernstein SL, Kerfeld CA. 2013. Biogenesis of a Bacterial Organelle: The Carboxysome Assembly Pathway. Cell 155:1131-1140.

673 51. Oltrogge LM, Chaijarasphong T, Chen AW, Bolin ER, Marqusee S, Savage DF. 2020.

674 Multivalent interactions between CsoS2 and Rubisco mediate $\alpha$-carboxysome formation. Nat Struct Mol Biol 27:281-287.

676 52. Wang H, Yan X, Aigner H, Bracher A, Nguyen ND, Hee WY, Long BM, Price GD, Hartl FU, Hayer-Hartl M. 2019. Rubisco condensate formation by CcmM in beta-carboxysome biogenesis. Nature2019/01/25. 566:131-135.

679 53. Freeman Rosenzweig ES, Xu B, Kuhn Cuellar L, Martinez-Sanchez A, Schaffer M,

Strauss M, Cartwright HN, Ronceray P, Plitzko JM, Förster F, Wingreen NS, Engel BD, Mackinder LCM, Jonikas MC. 2017. The Eukaryotic CO2-Concentrating Organelle Is

683 54. Horvath DJ, Li B, Casper T, Partida-Sanchez S, Hunstad DA, Hultgren SJ, Justice SS. 2011. Morphological plasticity promotes resistance to phagocyte killing of uropathogenic Escherichia coli. Microbes Infect 13:426-437.

686 55. Justice SS, Hung C, Theriot JA, Fletcher DA, Anderson GG, Footer MJ, Hultgren SJ. 2004. Differentiation and developmental pathways of uropathogenic Escherichia coli in urinary tract pathogenesis. Proc Natl Acad Sci 101:1333-1338. 
56. Kreuzer KN. 2013. DNA Damage Responses in Prokaryotes: Regulating Gene Expression, Modulating Growth Patterns, and Manipulating Replication Forks. Cold Spring Harb Perspect Biol 5.

692 57. Justice SS, Hunstad DA, Cegelski L, Hultgren SJ. 2008. Morphological plasticity as a bacterial survival strategy. Nat Rev Microbiol 6:162-168.

694 58. Heinrich K, Leslie DJ, Morlock M, Bertilsson S, Jonas K. 2019. Molecular basis and ecological relevance of Caulobacter cell filamentation in freshwater habitats. MBio 10.

59. Bos J, Zhang Q, Vyawahare S, Rogers E, Rosenberg SM, Austin RH. 2015. Emergence of antibiotic resistance from multinucleated bacterial filaments. Proc Natl Acad Sci 112:178 LP - 183.

60. Wehrens M, Ershov D, Rozendaal R, Walker N, Schultz D, Kishony R, Levin PA, Tans SJ. 2018. Size Laws and Division Ring Dynamics in Filamentous Escherichia coli cells. Curr Biol 28:972-979.e5.

702 61. Yang DC, Blair KM, Salama NR. 2016. Staying in Shape: the Impact of Cell Shape on Bacterial Survival in Diverse Environments. Microbiol Mol Biol Rev 80:187 LP - 203.

704 62. Wortinger MA, Quardokus EM, Brun Y V. 1998. Morphological adaptation and inhibition of cell division during stationary phase in Caulobacter crescentus. Mol Microbiol 29:963973.

707 63. Pernthaler J, Zöllner E, Warnecke F, Jürgens K. 2004. Bloom of filamentous bacteria in a mesotrophic lake: Identity and potential controlling mechanism. Appl Environ Microbiol

710 64. Pernthaler J. 2005. Predation on prokaryotes in the water column and its ecological 711 implications. Nat Rev Microbiol 3:537-546. 
712 65. Hahn MW, Moore ERB, Höfle MG. 1999. Bacterial Filament Formation, a Defense

713 Mechanism against Flagellate Grazing, Is Growth Rate Controlled in Bacteria of Different

714 Phyla. Appl Environ Microbiol 65:25 LP - 35.

715 66. Simek K, Vrba J, Pernthaler J, Posch T, Hartman P, Nedoma J, Psenner R. 1997.

716 Morphological and compositional shifts in an experimental bacterial community

717 influenced by protists with contrasting feeding modes. Appl Environ Microbiol 63:587 LP

$718-595$

719 67. Liao Y, Rust MJ. 2018. The Min Oscillator Defines Sites of Asymmetric Cell Division in

$720 \quad$ Cyanobacteria during Stress Recovery. Cell Syst.

721 68. Broddrick JT, Welkie DG, Jallet D, Golden SS, Peers G, Palsson BO. 2019. Predicting the metabolic capabilities of Synechococcus elongatus PCC 7942 adapted to different light regimes. Metab Eng.

724 69. Murayama Y, Kori H, Oshima C, Kondo T, Iwasaki H, Ito H. 2017. Low temperature 725 nullifies the circadian clock in cyanobacteria through Hopf bifurcation. Proc Natl Acad $726 \quad$ Sci U S A.

727 70. Muraleedharan S, Freitas C, Mann P, Glatter T, Ringgaard S. 2018. A cell length728 dependent transition in MinD-dynamics promotes a switch in division-site placement and 729 preservation of proliferating elongated Vibrio parahaemolyticus swarmer cells. Mol $730 \quad$ Microbiol 109:365-384.

731 71. MacCready JS, Vecchiarelli AG. 2018. In long bacterial cells, the Min system can act off$732 \quad$ center. Mol Microbiol 109:268-272.

733 72. Raghunathan S, Chimthanawala A, Krishna S, Vecchiarelli AG, Badrinarayanan A. 2020. 734 Asymmetric chromosome segregation and cell division in DNA damage-induced bacterial 
filaments. bioRxiv 2020.03.16.993485.

736 73. Cayron J, Dedieu A, Lesterlin C. 2020. Bacterial filament division dynamics allows rapid

737 post-stress cell proliferation. bioRxiv 2020.03.16.993345.

738 74. Gibson DG, Young L, Chuang RY, Venter JC, Hutchison CA, Smith HO. 2009.

739 Enzymatic assembly of DNA molecules up to several hundred kilobases. Nat Methods.

740 75. Clerico EM, Ditty JL, Golden SS. 2007. Specialized Techniques for Site-Directed

741 Mutagenesis in Cyanobacteria, p. 155-171. In . Humana Press.

742 76. Schindelin J, Arganda-Carreras I, Frise E, Kaynig V, Longair M, Pietzsch T, Preibisch S,

743 Rueden C, Saalfeld S, Schmid B, Tinevez J-Y, White DJ, Hartenstein V, Eliceiri K,

744 Tomancak P, Cardona A. 2012. Fiji: an open-source platform for biological-image

$745 \quad$ analysis. Nat Methods 9:676-682.

746 77. Ducret A, Quardokus EM, Brun Y V. 2016. MicrobeJ, a tool for high throughput bacterial 747 cell detection and quantitative analysis. Nat Microbiol 1:1-7. 
758 Table 1: Strains used in this study

\begin{tabular}{|c|c|c|}
\hline Strain & Description & Source \\
\hline $\begin{array}{l}\text { Synechococcus elongatus } \\
\text { PCC7942 }\end{array}$ & Wild Type & - \\
\hline $\begin{array}{l}\text { Synechococcus elongatus } \\
\text { PCC7942 }\end{array}$ & $\Delta m c d A$ & $(16)$ \\
\hline $\begin{array}{l}\text { Synechococcus elongatus } \\
\text { PCC7942 }\end{array}$ & $\Delta m c d B$ & $(16)$ \\
\hline $\begin{array}{l}\text { Synechococcus elongatus } \\
\text { PCC7942 }\end{array}$ & $\triangle m c d A B$ & $(16)$ \\
\hline $\begin{array}{l}\text { Synechococcus elongatus } \\
\text { PCC7942 }\end{array}$ & $r b c S-m T Q$ & $\begin{array}{l}\text { Wild Type transformed with } \\
\text { pAH40 }\end{array}$ \\
\hline $\begin{array}{l}\text { Synechococcus elongatus } \\
\text { PCC7942 }\end{array}$ & $\Delta m c d A+r b c S-m T Q$ & $\Delta m c d A$ transformed with $\mathrm{pAH} 40$ \\
\hline $\begin{array}{l}\text { Synechococcus elongatus } \\
\text { PCC7942 }\end{array}$ & $\Delta m c d B+r b c S-m T Q$ & $\Delta m c d B$ transformed with $\mathrm{pAH} 40$ \\
\hline $\begin{array}{l}\text { Synechococcus elongatus } \\
\text { PCC7942 }\end{array}$ & $\Delta m c d A B+r b c S-m T Q$ & $\Delta m c d A \mathrm{~B}$ transformed with $\mathrm{pAH} 40$ \\
\hline
\end{tabular}




\section{A}

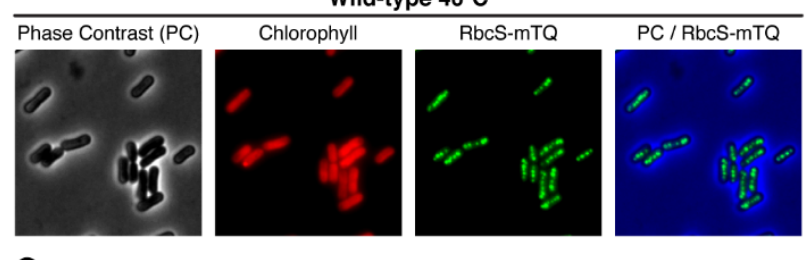

\section{C}

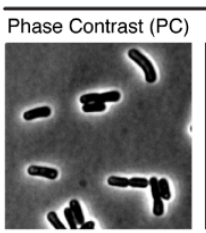

E

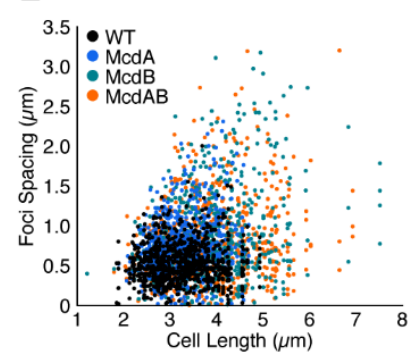

H

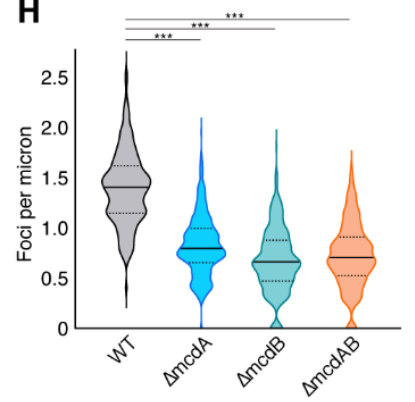

$\triangle m c d B 40^{\circ} \mathrm{C}$
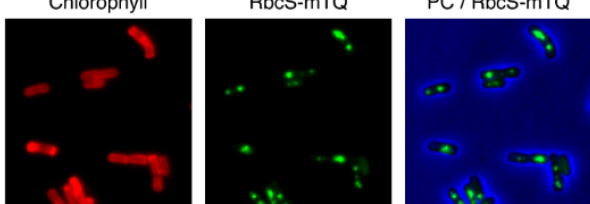

$\mathbf{F}$
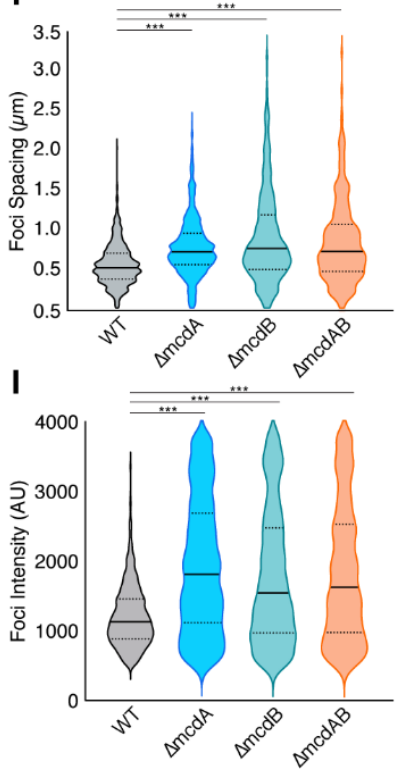

B

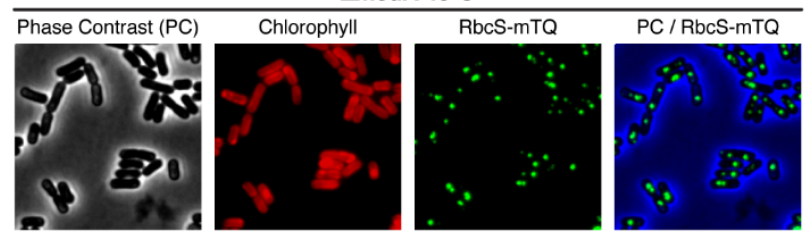

D $\triangle m c d A B 40^{\circ} \mathrm{C}$

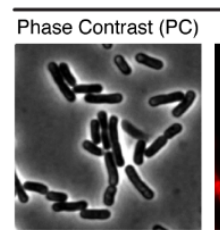

G

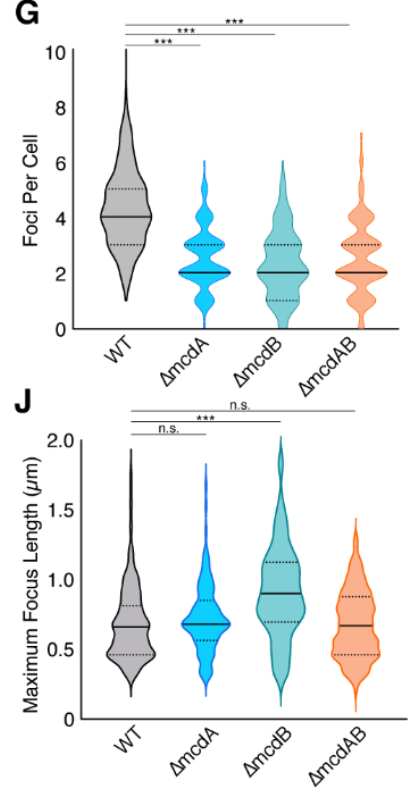

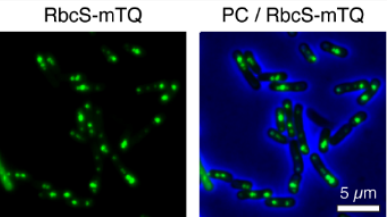

K

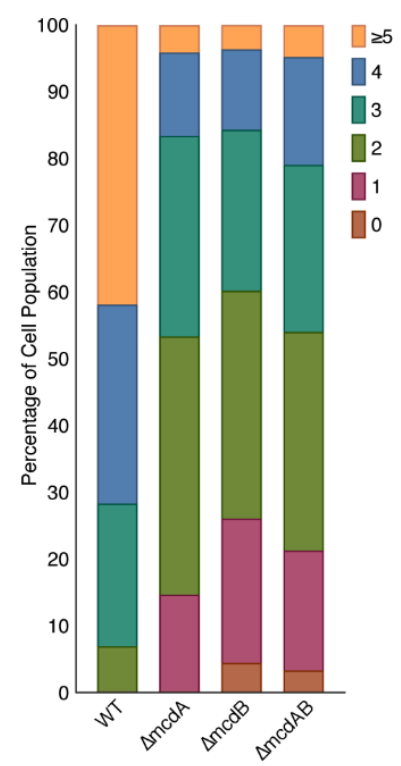

Figure 1. McdAB system mutants display fewer and mispositioned carboxysome aggregates at $40^{\circ} \mathrm{C}$. (A-D) Microscopy images of the specified cell strains grown at $40^{\circ} \mathrm{C}$ in $2 \% \mathrm{CO}_{2}$. Phase contrast (black), chlorophyll (red), and carboxysomes (green). Phase Contrast (PC) channel is blue in the merge for better contrast. (E) Spacing between carboxysome foci as a function of cell length. (F) Spacing between carboxysome foci in the same cell. (G) Carboxysome foci number per cell. (H) Number of carboxysome foci per unit cell length for each strain. (I) Carboxysome peak foci intensity for each cell strain. AU = Arbitrary Units. $(\mathbf{J})$ Quantification of the maximum length across carboxysome foci. (F-J) Solid bars represent the median and dashed lines demarcate the $95 \%$ confidence interval. Statistical significance was based on a nonparametric Mann-Whitney test. $* * *=\mathrm{P}<0.001,{ }^{* *}=\mathrm{P}<0.01, *=\mathrm{P}<0.05$, n.s. $=$ not significant. (K) Population percentages of cells with the specified number of carboxysome foci. $n \geq 1000$ carboxysomes from 440 cells of each strain. 
A

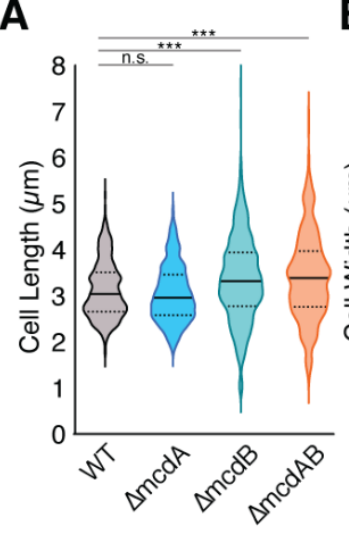

D

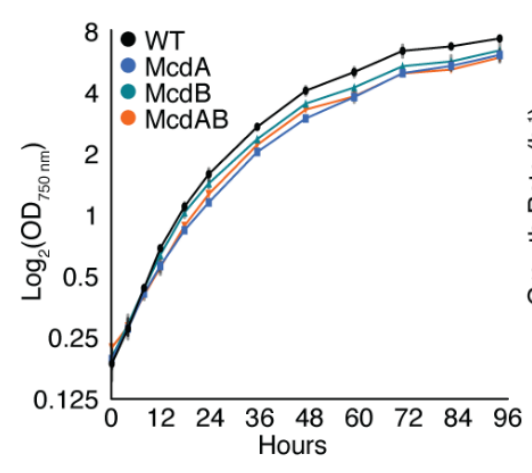

$\mathbf{F}$

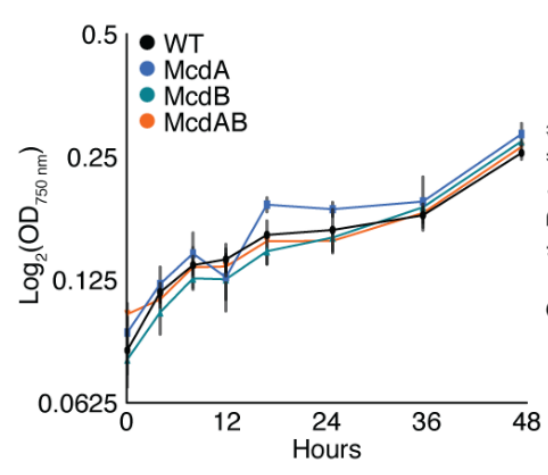

B

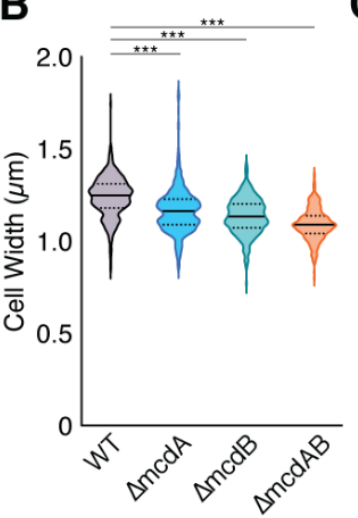

C $\square$ Symmetric

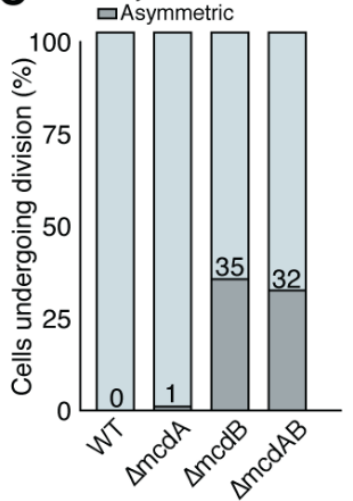

E

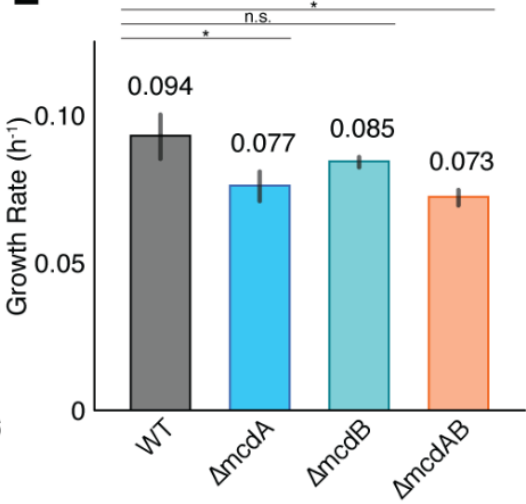

G

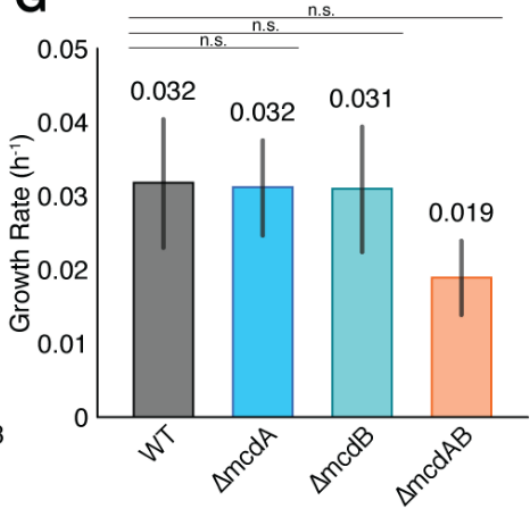

Figure 2. Carboxysome mispositioning correlates with subtle changes in cell physiology at $40^{\circ} \mathrm{C}$. (A) Cell lengths and (B) widths of WT population compared to McdAB system mutants. Cells were grown at in $2 \% \mathrm{CO}_{2} . \mathrm{n}=440$ cells of each strain. Statistical significance was based on a nonparametric Mann-Whitney test. $* * *=\mathrm{P}<0.001, * *=\mathrm{P}<0.01, *=\mathrm{P}<0.05$, n.s. $=$ not significant. (C) Percentage of cells undergoing symmetric (mid-cell; light grey bar) or asymmetric (non-mid-cell; dark grey bar) division. (D) Growth curves of all strains grown at $40{ }^{\circ} \mathrm{C}$ in $2 \% \mathrm{CO}_{2}$. (E) Quantification of mean exponential growth rate at $40^{\circ} \mathrm{C}$ in $2 \% \mathrm{CO}_{2}$. (F) Growth curves of all strains grown at $40^{\circ} \mathrm{C}$ in $0.4 \% \mathrm{CO}_{2}$. (G) Quantification of mean exponential growth rate at $40^{\circ} \mathrm{C}$ in $0.4 \% \mathrm{CO}_{2}$. (D-G) Error bars represent the standard deviation from three independent biological replicates. Statistical significance was based on an unpaired t-test. $* * *=$ $\mathrm{P}<0.001,{ }^{* *}=\mathrm{P}<0.01,{ }^{*}=\mathrm{P}<0.05$, n.s. $=$ not significant. 
A

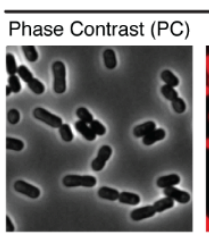

C

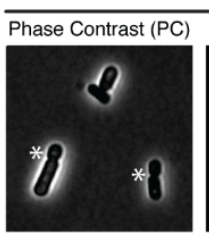

E

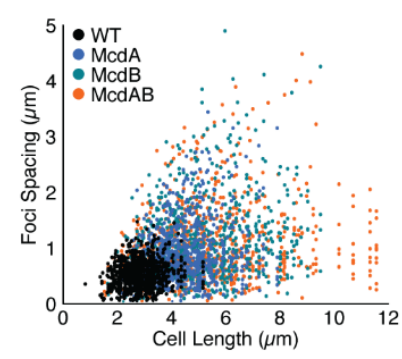

H
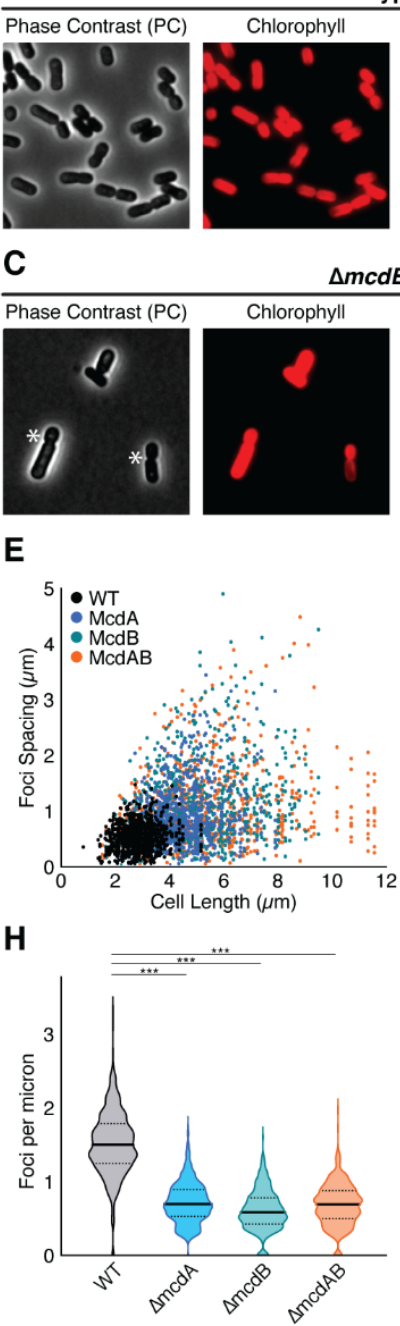

Wild-type $30^{\circ} \mathrm{C}$

$\Delta m c d B 30^{\circ} \mathrm{C}$
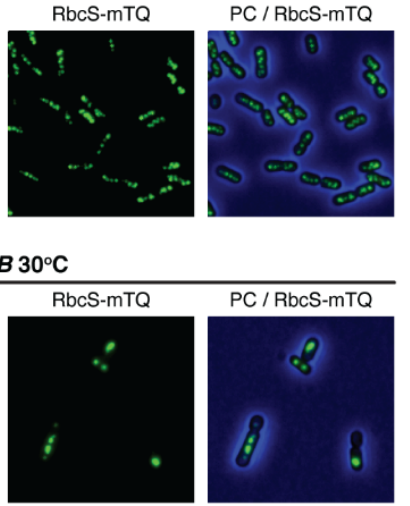

F
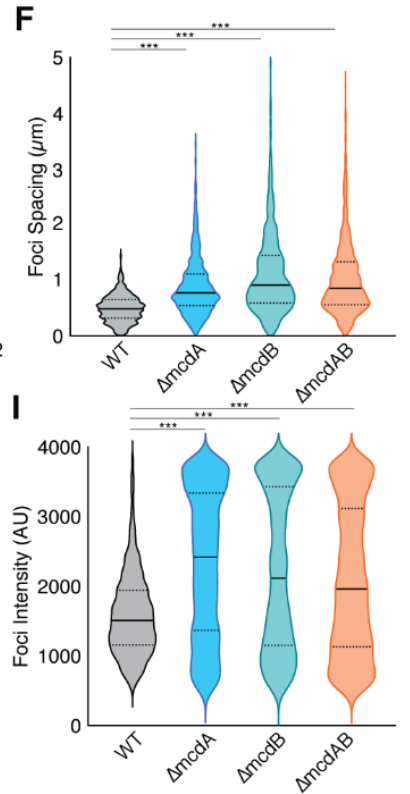

B

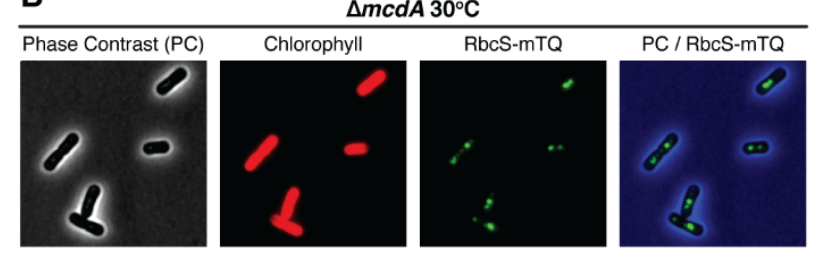

D

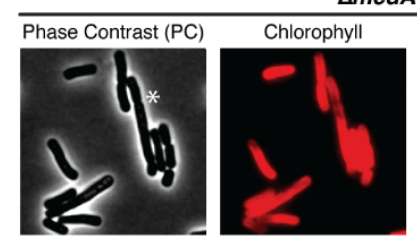

G

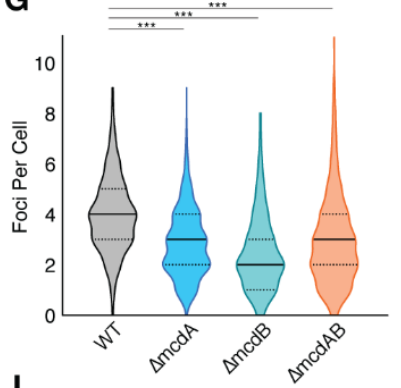

J

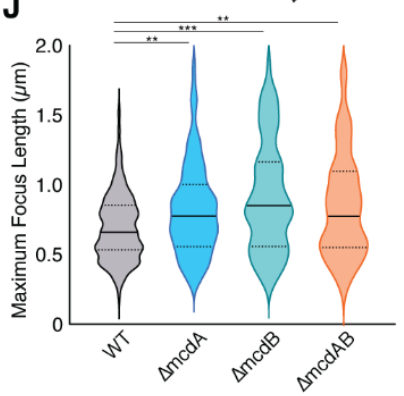

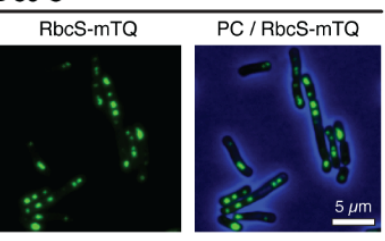

$\mathbf{K}$

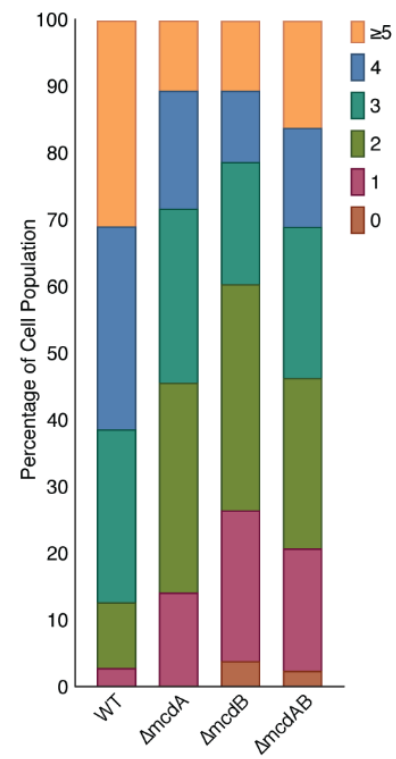

Figure 3. McdAB system mutants house few and mispositioned carboxysome aggregates at $30^{\circ} \mathrm{C}$. (A-D) Microscopy images of the specified cell strains grown in $2 \% \mathrm{CO}_{2}$. Phase contrast (black), chlorophyll (red), and carboxysomes (green). Phase Contrast (PC) channel is blue in the merge for better contrast. (E) Spacing between carboxysome foci as a function of cell length. (F) Spacing between carboxysome foci in the same cell. (G) Carboxysome foci number per cell. (H) Number of carboxysome foci per unit cell length for each strain. (I) Carboxysome peak foci intensity for each cell strain. Arbitrary Units (AU). (J) Quantification of the maximum length across carboxysome foci. (F-J) Solid bars represent the median and dashed lines demarcate the $95 \%$ confidence interval. Statistical significance was based on a nonparametric Mann-Whitney test. $* * *=\mathrm{P}<0.001, * *=\mathrm{P}<0.01, *=\mathrm{P}<0.05$, n.s. $=$ not significant. (K) Population

800 percentages of cells with the specified number of carboxysome foci. $n \geq 1000$ carboxysomes 801 from 440 cells of each strain. 
A

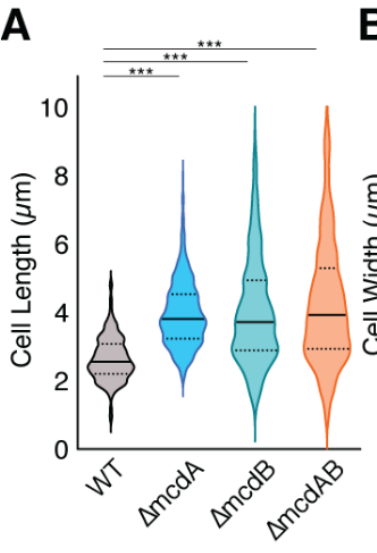

D

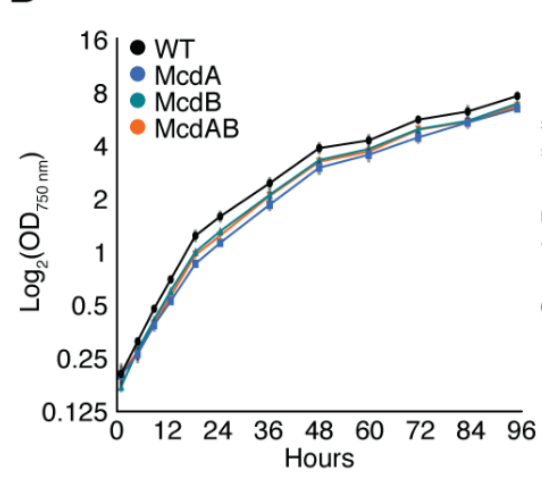

$\mathbf{F}$

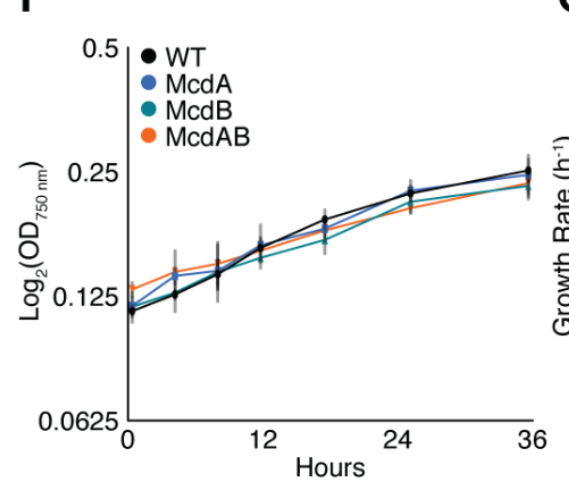

C $\square$ Symmetric

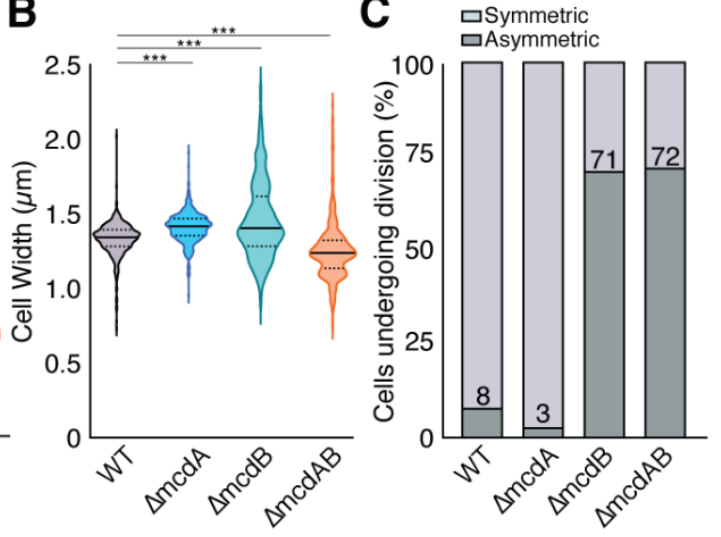

E

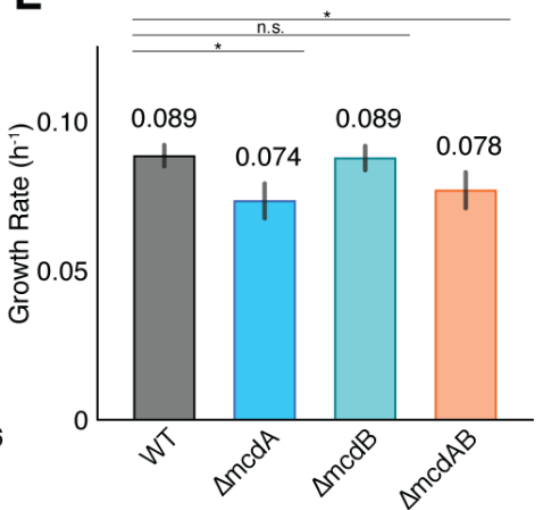

G

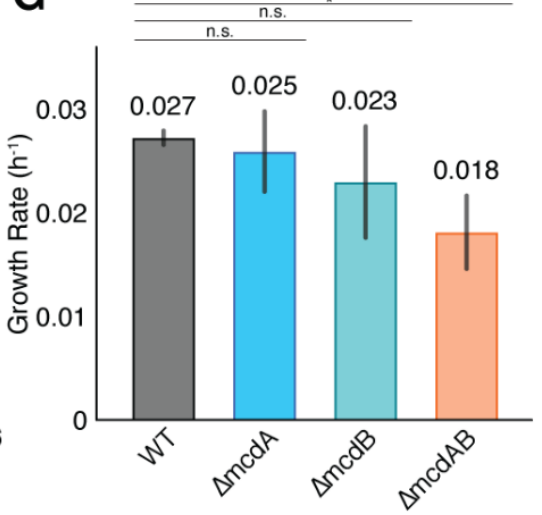

Figure 4. McdAB mutants display cell elongation and asymmetric cell division phenotypes at $30^{\circ} \mathrm{C}$. (A) Cell lengths and (B) widths of WT population compared to McdAB system mutants. Cells were grown in $2 \% \mathrm{CO}_{2} . \mathrm{n}=440$ cells of each strain. Statistical significance was based on a nonparametric Mann-Whitney test. $* * *=\mathrm{P}<0.001, * *=\mathrm{P}<0.01, *=\mathrm{P}<0.05$, n.s. $=$ not significant. (C) Percentage of cells undergoing symmetric (mid-cell; light grey bar) or asymmetric (non-mid-cell; dark grey bar) division. (D) Growth curves of all strains grown at $30^{\circ} \mathrm{C}$ in $2 \% \mathrm{CO}_{2}$. (E) Quantification of mean exponential growth rate at $30^{\circ} \mathrm{C}$ in $2 \% \mathrm{CO}_{2}$. (F) Growth curves of all strains grown at $30^{\circ} \mathrm{C}$ in $0.4 \% \mathrm{CO}_{2}$. (G) Quantification of mean exponential growth rate at $30^{\circ} \mathrm{C}$ in $0.4 \% \mathrm{CO}_{2}$. (D-G) Error bars represent the standard deviation from three independent biological replicates. Statistical significance was based on an unpaired t-test. $* * *=$ $\mathrm{P}<0.001,{ }^{* *}=\mathrm{P}<0.01,{ }^{*}=\mathrm{P}<0.05$, n.s. $=$ not significant. 


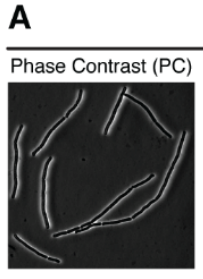

C

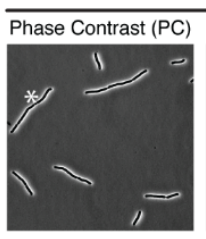

E

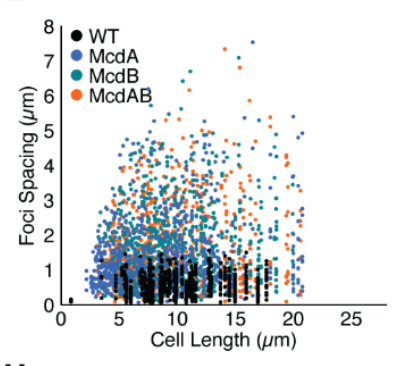

H
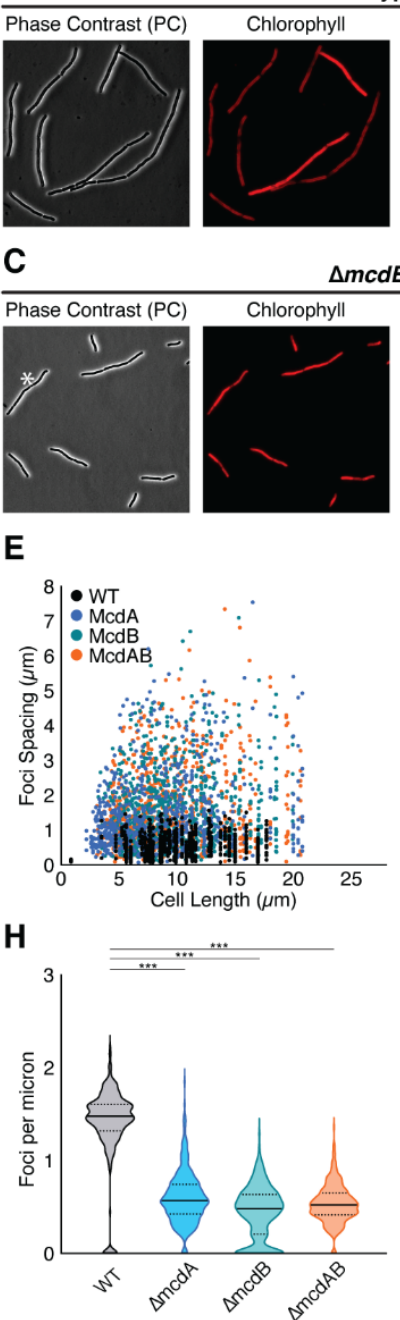

Wild-type $20^{\circ} \mathrm{C}$

$\triangle m c d B 20^{\circ} \mathrm{C}$
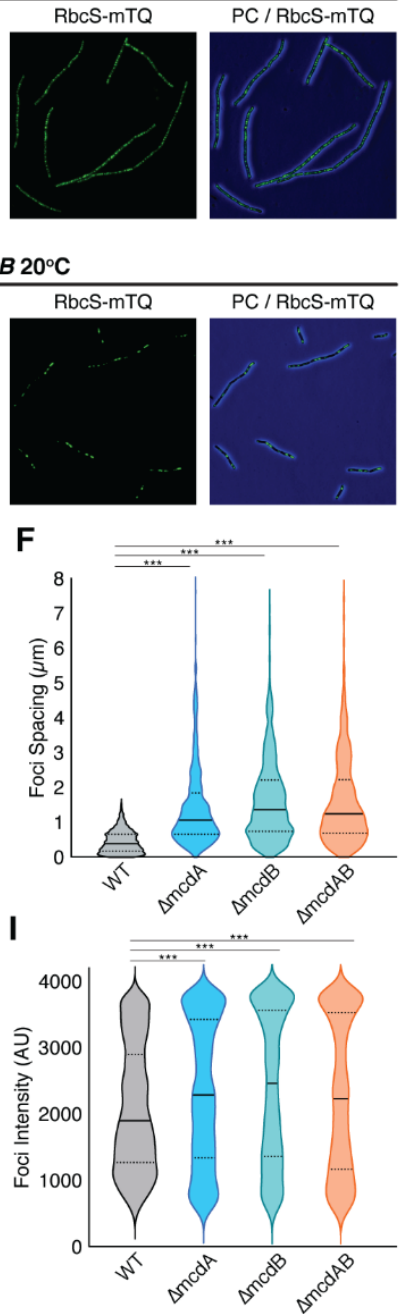

B

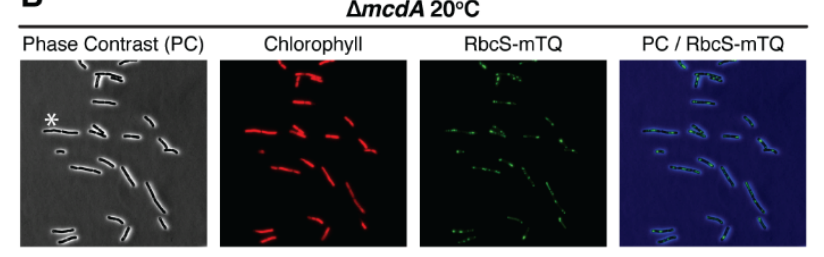

D

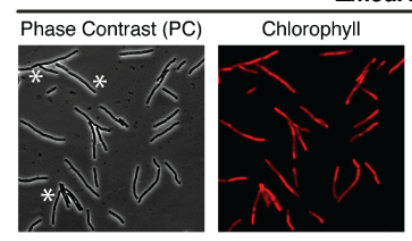

G
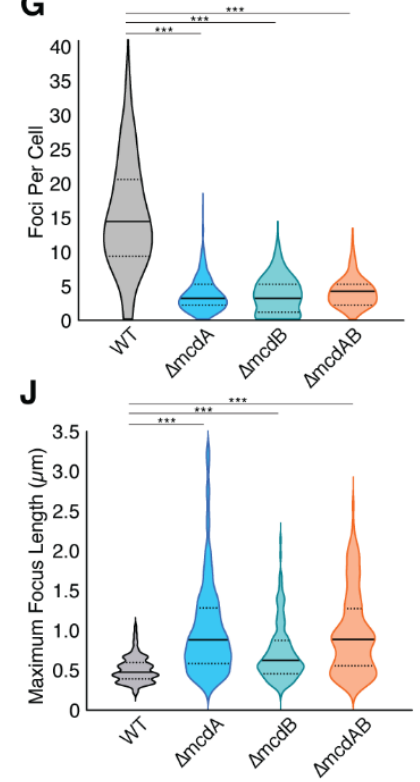

$\triangle m c d A B 20^{\circ} \mathrm{C}$

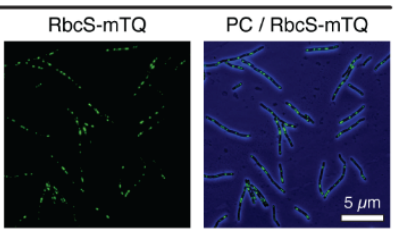

K

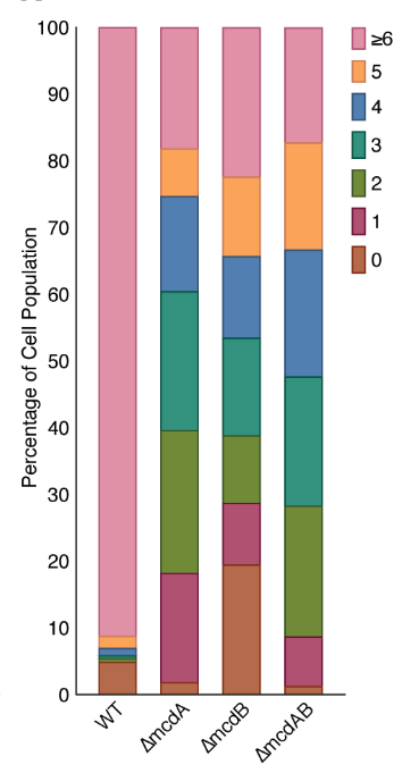

Figure 5. At $20^{\circ} \mathrm{C}$ wild-type and $\mathrm{McdAB}$ system mutants elongate, but only the mutants display few and mispositioned carboxysome aggregates. (A-D) Microscopy images of the specified cell strains grown in $2 \% \mathrm{CO}_{2}$. Phase contrast (black), chlorophyll (red), and carboxysomes (green). Phase Contrast (PC) channel is blue in the merge for better contrast. (E) Spacing between carboxysome foci as a function of cell length. (F) Spacing between carboxysome foci in the same cell. (G) Carboxysome foci number per cell. (H) Number of carboxysome foci per unit cell length for each strain. (I) Carboxysome peak foci intensity for each cell strain. AU = Arbitrary Units. (J) Quantification of the maximum length across carboxysome foci. (F-J) Solid bars represent the median and dashed lines demarcate the $95 \%$ confidence interval. Statistical significance was based on a nonparametric Mann-Whitney test. $* * *=\mathrm{P}<0.001, * *=\mathrm{P}<0.01$, *

$830=\mathrm{P}<0.05$, n.s. $=$ not significant. $(\mathbf{K})$ Population percentages of cells with the specified number 831 of carboxysome foci. $n \geq 1000$ carboxysomes from 440 cells of each strain. 
A

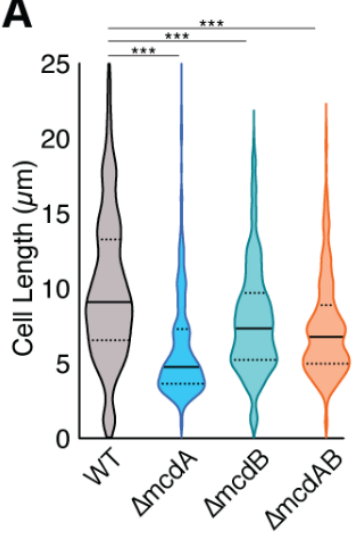

D

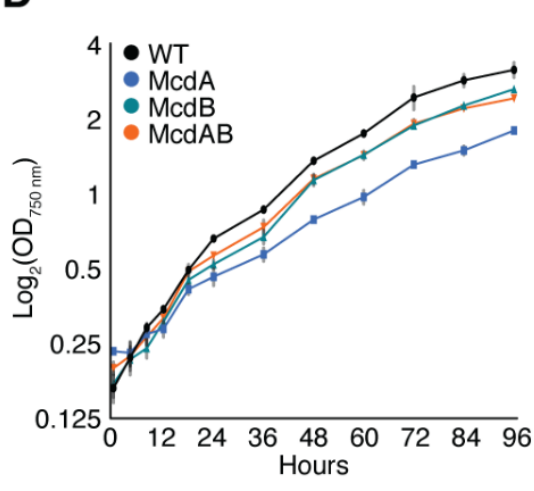

$\mathbf{F}$

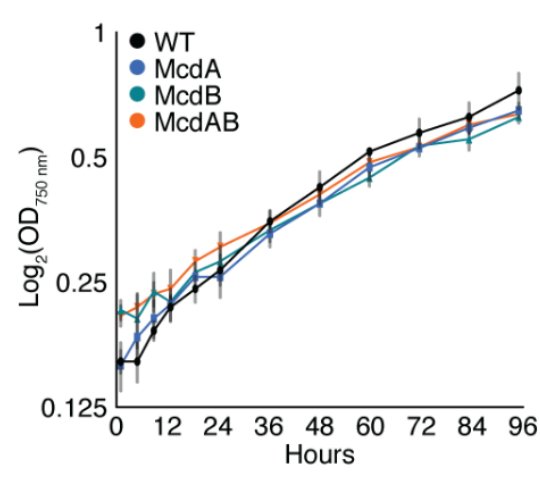

B

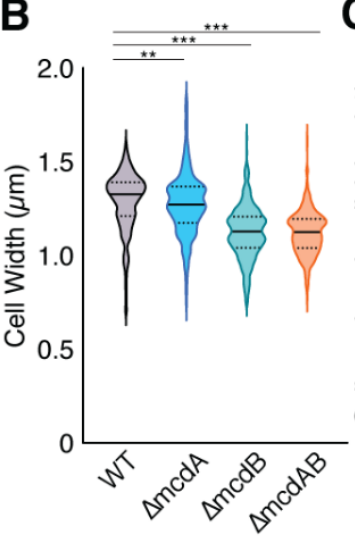

C aSymmetric

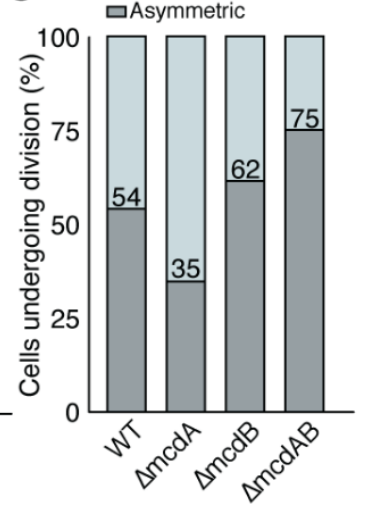

E

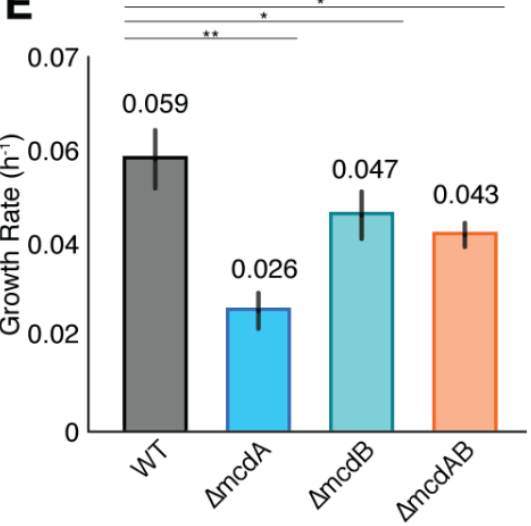

G

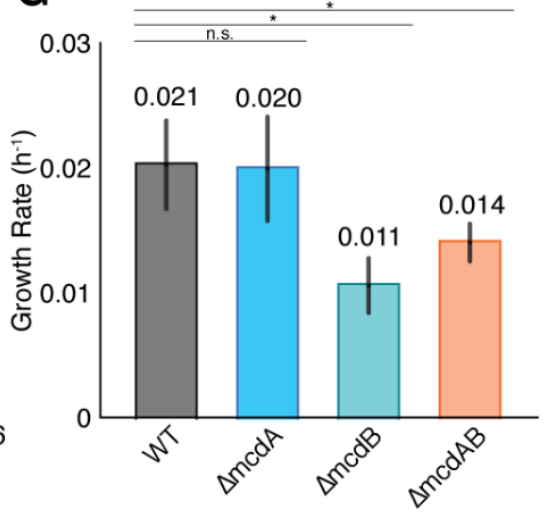

Figure 6. At $20^{\circ} \mathrm{C}$ wild-type and $\mathrm{Mcd} A B$ mutants elongate and undergo asymmetric cell division, but only mutants show slowed growth rates. (A) Cell lengths and (B) widths of WT population compared to McdAB system mutants. Cells were grown in $2 \% \mathrm{CO}_{2} . \mathrm{n}=440$ cells of each strain. Statistical significance was based on a nonparametric Mann-Whitney test. $* * *=\mathrm{P}<$ $0.001, * *=\mathrm{P}<0.01, *=\mathrm{P}<0.05$, n.s. $=$ not significant. (C) Percentage of cells undergoing symmetric (mid-cell; light grey bar) or asymmetric (non-mid-cell; dark grey bar) division. (D) Growth curves of all strains grown at $20^{\circ} \mathrm{C}$ in $2 \% \mathrm{CO}_{2}$. (E) Quantification of mean exponential growth rate at $20^{\circ} \mathrm{C}$ in $2 \% \mathrm{CO}_{2}$. (F) Growth curves of all strains grown at $20^{\circ} \mathrm{C}$ in $0.4 \% \mathrm{CO}_{2}$. $(\mathbf{G})$ Quantification of mean exponential growth rate at $20^{\circ} \mathrm{C}$ in $0.4 \% \mathrm{CO}_{2}$. (D-G) Error bars represent the standard deviation from three independent biological replicates. Statistical significance was based on an unpaired t-test. ${ }^{* *}=\mathrm{P}<0.001,{ }^{*}=\mathrm{P}<0.01, *=\mathrm{P}<0.05$, n.s. $=$ not significant. 

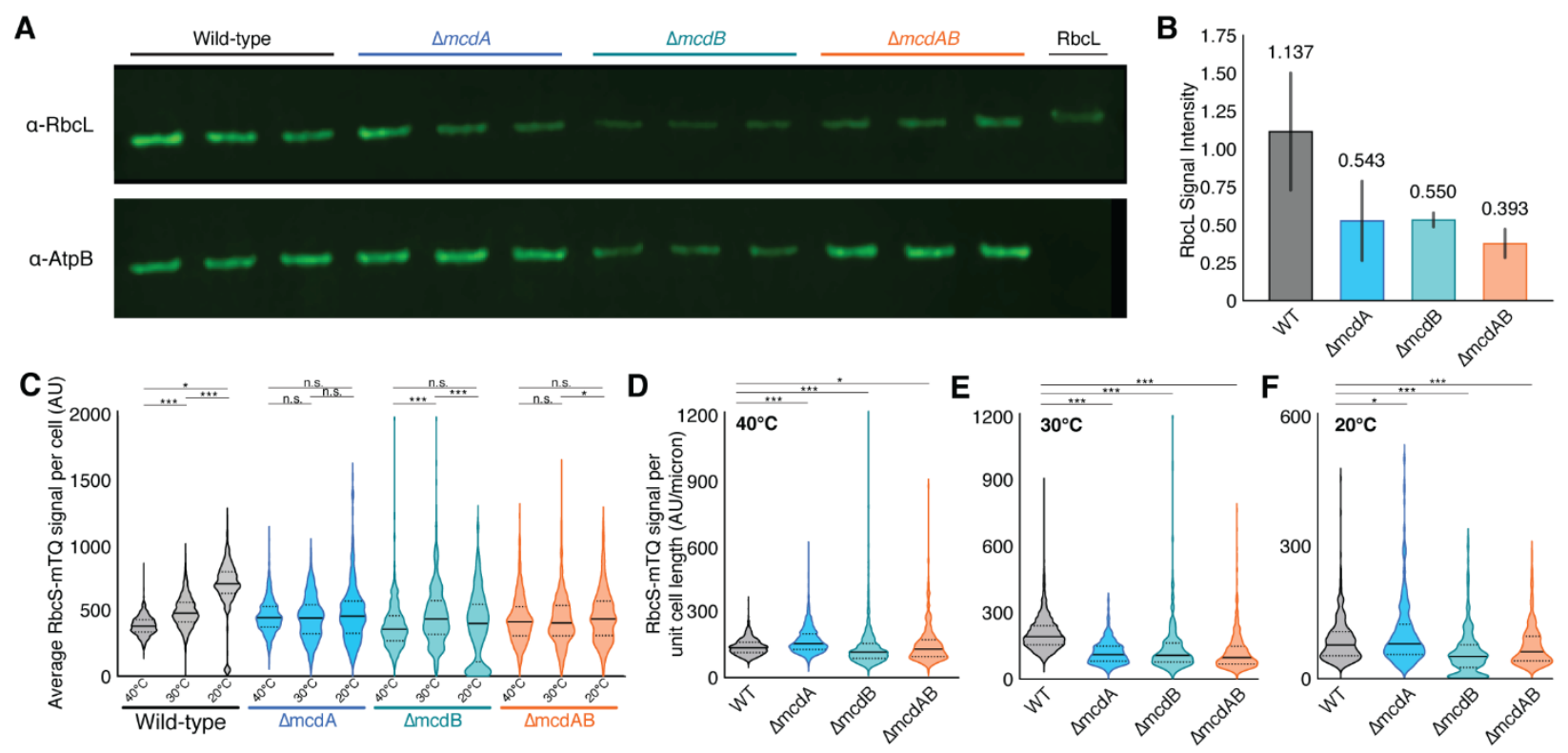

Figure 7. McdAB mutants have decreased cellular levels of RuBisCO. (A) Western Blot analysis of RbcL signal (top) and Atpß (bottom). Wild-type (lanes 1-3), $\Delta m c d A$ (lanes 4-6), $\triangle m c d B$ (lanes 7-9), and $\triangle m c d A B$ (lanes 10-12), purified RbcL control (lane 13).

Quantification of immunoblot signal for the cell type specified normalized against Atp $\beta$ signal. Cells were grown at $30^{\circ} \mathrm{C}$ in $2 \% \mathrm{CO}_{2}$. Error bars represent the standard deviation from three independent biological replicates. (C) Quantification of the average RbcS-mTQ intensity per cell in each strain at the specified temperatures. (D-F) Quantification of the average RbcS-mTQ intensity normalized to cell length in each strain at the specified temperatures. $n \geq 338$ per cell population. Statistical significance was based on an unpaired t-test. $* * *=\mathrm{P}<0.001, * *=\mathrm{P}<$ $0.01, *=\mathrm{P}<0.05$, n.s. $=$ not significant. 

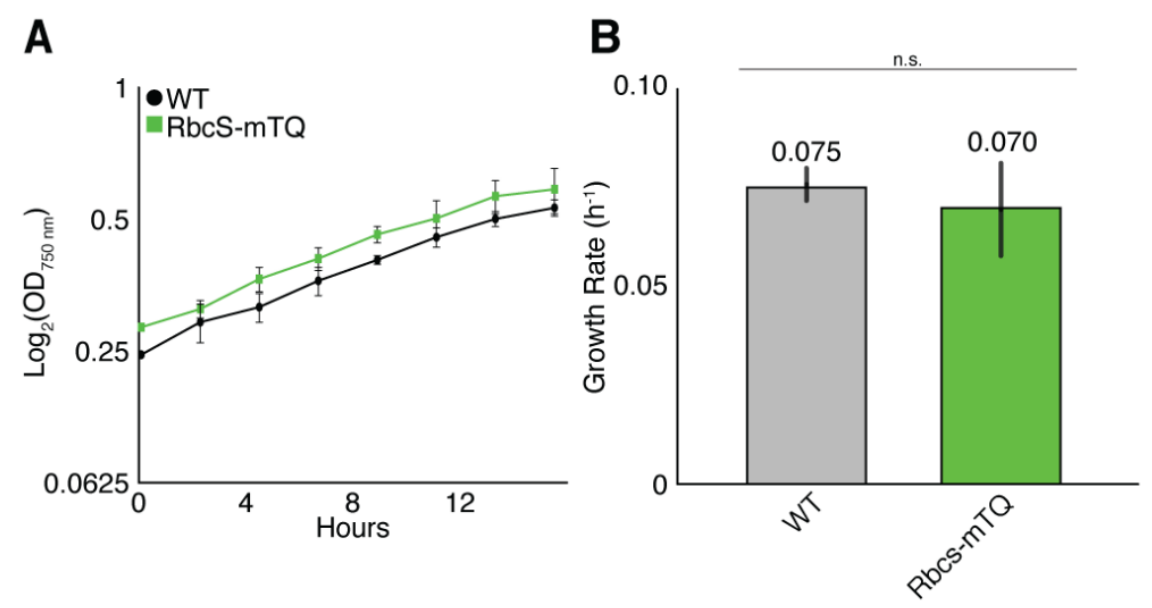

881

882

883

884

885

886

Figure S1. Presence of RbsC-mTQ carboxysome marker does not influence growth. (A) Growth curves of wild-type $S$. elongatus with and without RbcS-mTQ carboxysome marker. Cells were grown at $30^{\circ} \mathrm{C}$ in $2 \% \mathrm{CO}_{2}$. (B) Comparison of growth rates. Error bars represent the standard deviation from three independent biological replicates. Unpaired t-test shows growth rates were not statistically different.

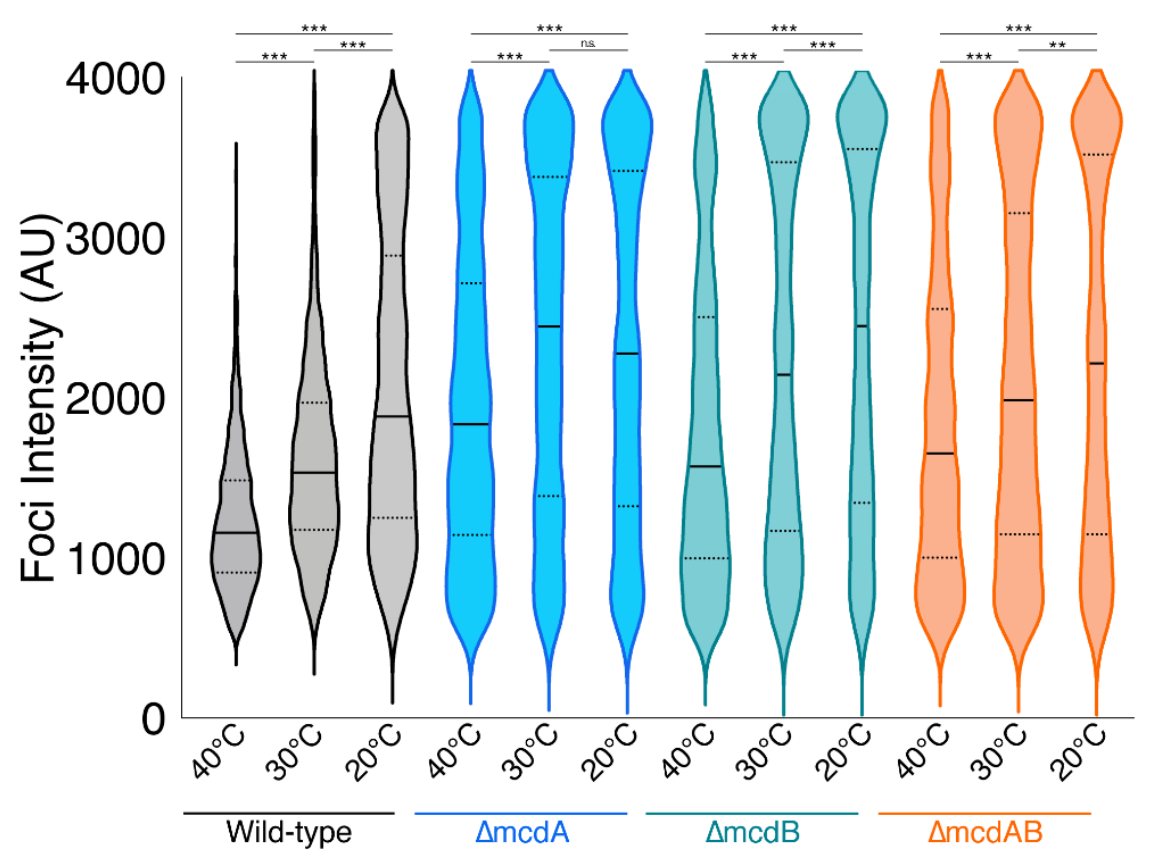

Figure S2. Comparison of the peak RbcS-mTQ foci intensities for each strain across the three growth temperatures tested in this study. AU = Arbitrary Units AU. $n>1000$ carboxysomes per cell-line at each temperature. Solid bars represent the median and dashed lines demarcate the $95 \%$ confidence interval. Statistical significance was based on a nonparametric Mann-Whitney test. $* * *=\mathrm{P}<0.001, * *=\mathrm{P}<0.01, *=\mathrm{P}<0.05$, n.s. $=$ not significant. 